\title{
A review on fabrication and characteristics of functionally graded aluminum matrix composites fabricated by centrifugal casting method
}

\author{
Rupesh Kumar Verma ${ }^{1} \cdot$ Digvijay Parganiha $^{1} \cdot$ Manoj Chopkar $^{1}$
}

Received: 27 August 2020 / Accepted: 12 January 2021 / Published online: 27 January 2021

(c) The Author(s) 2021 OPEN

\begin{abstract}
This paper delivers a detailed review of the influence of material and process variables on the microstructure, mechanical and tribological characteristics of functionally graded aluminum matrix composites (FGAMCs) produced by the ex-situ centrifugal casting method from previous studies. Also, the basic principle and classification of centrifugal casting to produce FGAMCs are illustrated. The ceramic reinforcement particles are classified based upon their uses in the processing of FGAMCs through the ex-situ centrifugal casting technique. In addition, using the linear regression model, an effort has been made to optimize the material and process variables to get enhance the mechanical properties. It is seen from the optimization while mold preheating temperature ranges $250-350^{\circ} \mathrm{C}$, centrifugal speed kept between 600 and $1300 \mathrm{rpm}$, pouring temperature in the range of $740-760^{\circ} \mathrm{C}$ having reinforcement particle of $10-15$ wt $\%$, with an average particle size of 18-50 $\mu \mathrm{m}$ yield the maximum of hardness and tensile strength. This paper aims to provide direction to future researchers to develop advanced material using this route and thus, to boost technological growth.
\end{abstract}

Keywords Functionally graded (or gradient) materials (FGMs) - Functionally graded aluminum matrix composites $($ FGAMCs) · Reinforcement ceramic particles · Ex-situ centrifugal casting

\section{Introduction}

Numerous engineering applications such as engine piston, cylinder liner, bearings, bushes, brake drums, brake disks, gears, tubes, and pipes require specific properties [1, 2]. The adequate performance of these components, which is not possible by conventional (pure metals, alloys) and traditional composite materials, can be achieved by using functionally graded materials (FGMs) [3-5]. The ceramics properties included high wear-resistant, frictional resistance, brittleness, and having high melting temperature, and metals are ductile and possessing high mechanical strength $[6,7]$. The addition of ceramic reinforcement particles into the metal matrix in a graded manner not only enhances the toughness and wear resistance but also overcomes the debonding of ceramic-metal so that the component can perform a specified function very well under extreme conditions $[8,9]$. For instance, the interior wall of the cylinder liner in the automotive system requires high wear resistance property in elevated temperature and pressure surroundings; it is necessary to design a sustainable material to satisfy the function and performance of the cylinder liner with improving engine life [10]. Thus with the design and proper combinations of the two different materials having distinct characteristics in a single component with graded distribution can overcome the problems in such engineering applications [11].

FGMs are advanced composite materials that can be tailored in such a way that the properties, microstructures, porosity, phases, and composition varies across the

Manoj Chopkar, mchopkar.mme@nitrr.ac.in | ${ }^{1}$ Department of Metallurgical and Materials Engineering, National Institute of Technology, Raipur 492010, India. 
volume of a product from one region to another [12-14]. The main difference between traditional composites and FGMs is the distribution of reinforcement particles. In conventional composite material, the distribution of reinforcement particles is found uniform, whereas, in FGMs, it is distributed in a gradient manner $[15,16]$. The idea of FGM is inspired by nature as it exists in teeth, skin, bone, bamboo [17]. In 1972, the idea of the first structural gradient FGM was proposed for composites and polymeric material, and the concept of compositional FGM as a thermal barrier was firstly adopted and implemented by Japan in 1984 during a spaceplane project [18]. Based on variation, FGMs can be of two types, continuous (Fig. 1a) and discontinuous (Fig. 1b) $[19,20]$. In the case of continuous FGMs, variation is found spatial continuously from one material to another. This variation is gradual in terms of microstructure, composition, and hence the properties. While in discontinuous FGMs, variation in a layered way is provided, resulting in a layer by layer, discrete changes in compositions with multi-layered interfaces [21]. The requirement of application of FGMs is becoming popular in various fields such as engineering, aerospace, biomedical, optoelectronics, chemical plants, energy sectors, nuclear reactors [22-25]. Many processing techniques have been developed to produce FGMs, such as powder stacking, spark plasma sintering, centrifugal casting, squeeze casting, solid free form method, and laser cladding [26-32].

Centrifugal casting is the most versatile and economical technique to produce FGMs amongst various processes [33]. This technique can be used to produce an FGM with continuous variation of the composition across the volume of a single component. In this study, the types and the principle behind the synthesis of FGMs have been described briefly. The discussions under this review are based on the effect of various factors such as the density of matrix, reinforcement particles, and their size, shape, weight, type of reinforcement particle. Further, an effort also has been made to understand the effect of parameters like, preheating temperature of molds and reinforcement particles, the viscosity of matrix, pouring temperature, centrifugal speeds involved during the production of FGM by centrifugal casting that plays a significant role not only to produce continuous variation but also to obtain improved mechanical and wear behavior. Figure 2 shows the yearwise publication trends as evidence of increasing attention towards the fabrication of FGMs using centrifuge casting technology.

Aluminum has been widely used by researchers as a matrix material to produce FGMs. Some endeavors have been accomplished to produce FGMs through centrifugal casting using magnesium, copper, and low carbon steel as metal matrix incorporation with ceramics [31, 34-36]. All metals have their own unique physical and mechanical characteristics redirected to the components produced by different manufacturing methods. Additionally, the strength of $\mathrm{Al}, \mathrm{Cu}$, and $\mathrm{Mg}$ alloys can be enriched with the aid of different ceramic materials with their distinct characteristics in a single component as per the requirement and application.

The review paper is mainly divided into five different sections dealing with the effect of material and process variables on the microstructure, mechanical, and tribological characteristics of FGAMCs fabricated through the ex-situ centrifugal casting technique. Section 1 discusses the basic principles behind the fabrication of continuous FGAMCs through the centrifugal casting method, and their types, processing, and strengthening mechanisms are highlighted. Section 2 describes the classification of ceramic reinforcement particles based upon their uses in the processing of FGAMCs through the ex-situ centrifugal casting technique, and also their effect on mechanical and wear properties are discussed in-depth with the material and process parameters. The optimization of various material and process variables to improve mechanical properties, mainly tensile strength, and hardness is presented in Sect. 3. Future scope and current research
Fig. 1 a Discontinuous and $\mathbf{b}$ Continuous FGMs $[19,20]$
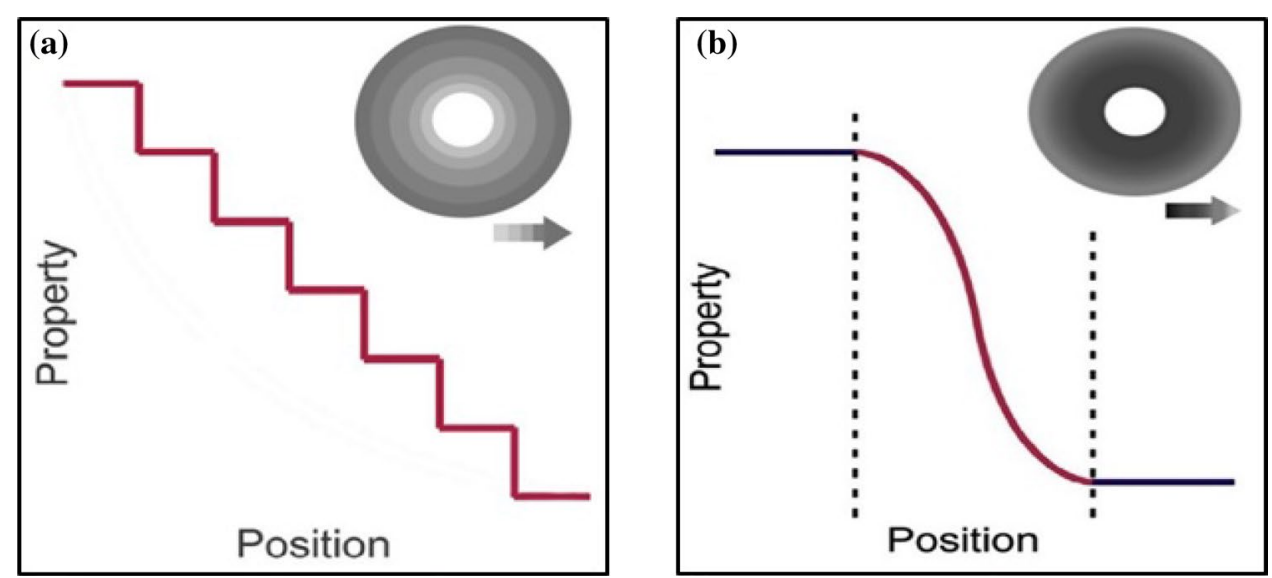
Fig. 2 Publications trends of FGAMC produced through the centrifugal casting method provided by scientific articles search engine Scopus and Sciencedirect

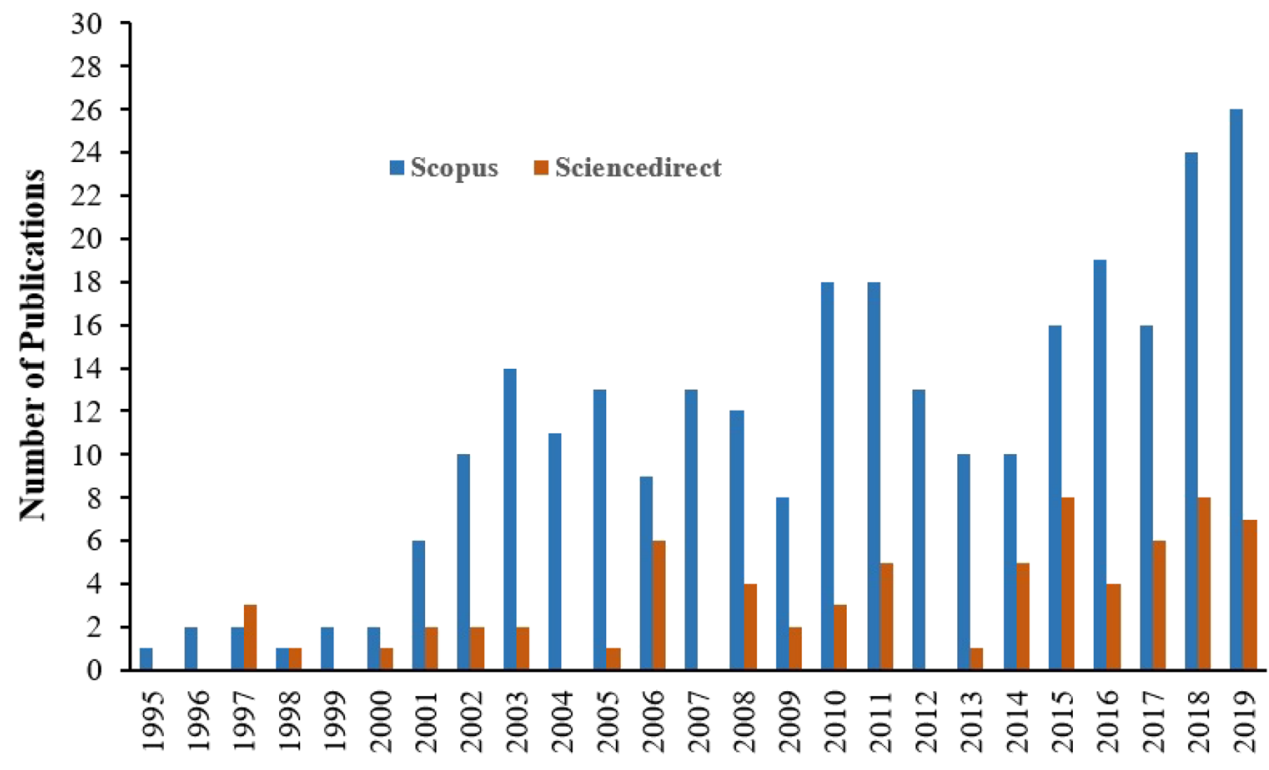

Years gaps are presented in Sect. 4, while summary and conclusions are presented in Sect. 5. Overall, the current edition of the research aims to benefit future researchers in FGM fabrication.

\subsection{Principle of centrifugal casting}

The centrifugal forces applied on the centrifugal casting machine mold are given by [37, 38]:

$F=\frac{M\left(V_{m}\right)^{2}}{r}$

where $\mathrm{F}$ is the centrifugal force on the machine mold in Newton, $V_{m}$ is the mold peripheral linear velocity in $\mathrm{m} / \mathrm{s}, \mathrm{M}$ is the mass of molten metal in gram, $r$ is the average radii of the rotating work-piece cylinder in the mold in meter.

Also, the $\mathrm{G}$ factor is given by [39]:

$\mathrm{G}=\frac{\text { Centrifugal Force acting on a rotating casting product }}{\text { Gravitational force }}$

$G=\frac{C F}{G F}=\frac{M\left(V_{m}\right)^{2}}{r \cdot M g}=\frac{\left(V_{m}\right)^{2}}{r . g}$

Centrifugal action is responsible for achieving the gradation in a composition primarily by the difference in density between the molten metal and solid particles. Under the centrifugal force, the motion of particles in a viscous liquid is given by Stokes' law [40]:

$\frac{\mathrm{dx}}{\mathrm{dt}}=\frac{\left|\rho_{\mathrm{p}}-\rho_{\mathrm{m}}\right| \mathrm{GgD}_{\mathrm{p}}^{2}}{18 \eta}$ where $\mathrm{dx} / \mathrm{dt}, \rho, G, g, D_{p}$, and $\eta$ are velocity, density, G factor, gravitational acceleration, particle diameter, and viscosity of the molten metal, respectively. The subscripts, ' $p$ ' and ' $m$ ', represent particle and matrix, respectively.

In addition, the distribution and velocity of particles during vertical centrifugal casting are affected by centrifugal force $F_{C}$ generated due to mold rotation, drag force $F_{D}$ due to viscosity of liquid metal, repulsive force or Van der Waal forces $F_{L}$ caused by solid-liquid interface movement, and gravitational force $\mathrm{F}_{\mathrm{G}}$. As the effect of gravitational force is very small, it is generally neglected $[41,42]$.

Force balance $F_{\text {net }}$ is calculated by equation

$F_{\text {net }}=F_{C}-F_{D}-F_{L}$

As the repulsive force $F_{L}$ is considerable on the particles near the solid wall, i.e., at the solid-liquid interface. The dynamic $F_{\text {net }}$ not induced by the solid-liquid interface is given by

$\mathrm{F}_{\text {net }}=\mathrm{F}_{\mathrm{C}}-\mathrm{F}_{\mathrm{G}}$

Considering the fluid flow as laminar $\left(R_{e} \leq 1\right), \mathrm{F}_{\text {net }}$ is given by equation

$\frac{4}{3} \pi R^{3} \rho_{p}\left(\frac{d^{2} r}{d t}\right)=\frac{4}{3} \pi R^{3}\left(\rho_{p}-\rho_{m}\right) \omega^{2} r-6 \pi R \mu\left(\frac{d r}{d t}\right)$

By the solution of Eq. (6), the position of the particle not influenced by the repulsive force $F_{L}$ moving at a constant velocity at any time $t$ is given by

$r(t)=r_{0} \exp \left[\frac{4 \omega^{2}\left(\rho_{p}-\rho_{m}\right) R^{2} t}{18 \mu}\right]$ 
where $r_{0}$ is the position of the particle at time $t=0$.

In vertical centrifugal casting, the resultant force is constant, whereas, in horizontal centrifugal casting, the centrifugal force is intermittently varied by gravity and intrinsic vibrations [43].

\subsection{Processing of FGM by centrifugal casting}

The processing of FGM can be broadly divided into two bases. Figure 3 shows the classification of the Centrifugal casting technique to produce FGMs [44-47].

Horizontal centrifugal casting technique is best applied to castings of greater length than the diameter and which have a cylindrical bore, for example-rings, cylinder liners, pipes, brake drums, bearings, sleeves.

Vertical centrifugal casting is generally used for cylindrical shapes in which the diameter is greater than the length (or height) of the casting, such as-valve, sheaves, gear blanks, disc brake, electric motor rotors, and sprockets.

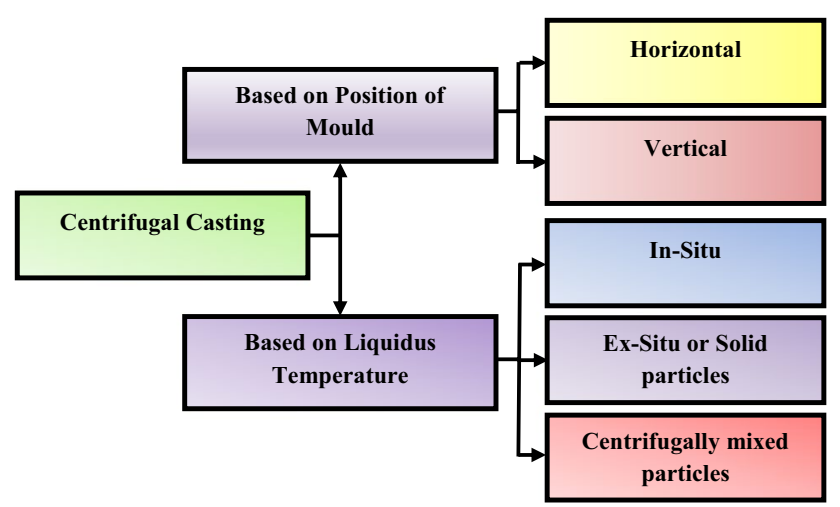

In-situ centrifugal casting technique is a method in which the formation of reinforcement takes place within the matrix during the processing.

In ex-situ centrifugal casting technique, the reinforcement particle is externally added into the matrix to produce FGMs.

Centrifugally mixed particle method is a special technique to develop FGM in which matrix and reinforcement particle are mixed together and placed inside the rotating mold, then molten matrix metal is poured into the rotating mold.

Synthesis of functionally graded aluminum matrix composites by ex-situ centrifugal casting consists of two steps (Fig. 4)-stir casting followed by centrifugal casting [48, 49]. In the first step, preheated reinforcement particles are added into the liquid metal matrix at a particular temperature then mixed uniformly at a particular speed using a mechanical stirrer (Fig. 4a). The subsequent step involves pouring this uniform mixture into a rotating mold (Fig. 4b).

\subsection{Strengthening mechanism of FMGACs developed for improving mechanical properties}

The review focuses on the production of FMGACs that are used for mechanical applications. When developing an alloy, the common aspect is to improve its mechanical properties. In the FGAMCs family, the common improvement concerns are hardness, tensile, and wear properties.

All the strengthening mechanisms use the disturbance to the dislocation pathway, but still, there are few areas with low impediments which ensure ductility. The areas containing the reinforcement particles exhibit higher hardness than that of free areas in the same material. It is worth attempting to note the changes in the mechanical

Fig. 3 Classification of centrifugal casting technique [44-47]

Fig. 4 Steps in processing FGMs via centrifugal casting followed by stir casting $[48,49]$

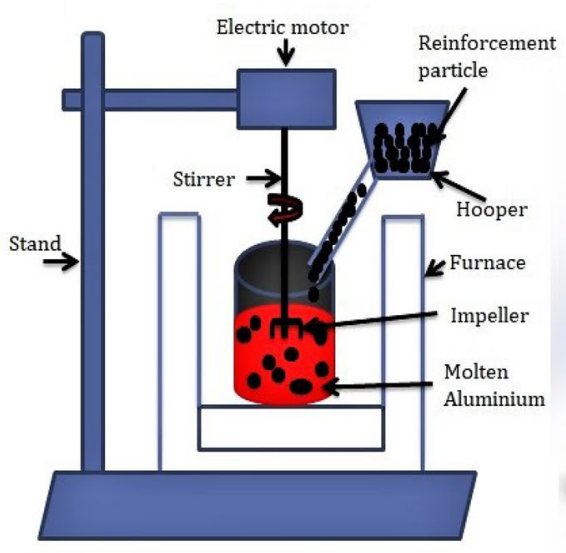

(a) Step-1: Mixing of reinforcement particles with molten metal matrix

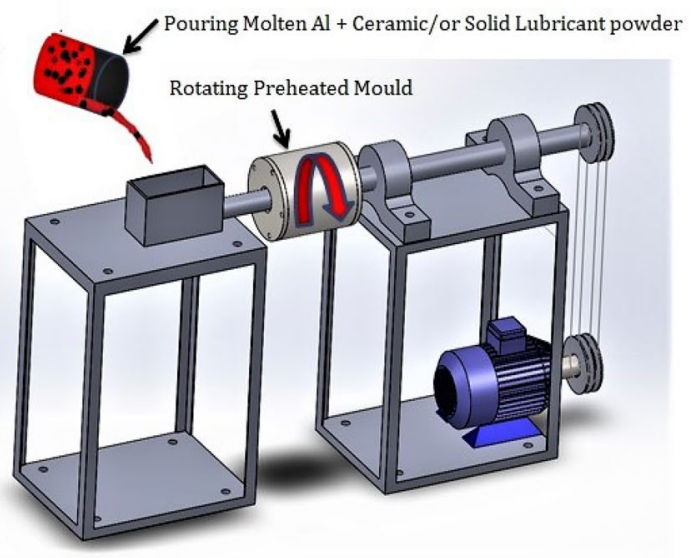

(b) Step-2: Synthesis of FGM through centrifugal casting 
properties with the changes in the microstructure. The strength of FGAMCs is dependent on the five mechanisms.

1. Dispersion hardening Dispersion strengthening is the addition of the second phase hard particle inside the matrix. This process produces dislocation pinning sites inside the material. The strengthening is due to dislocation motion in the metal being impeded by the presence of small, hard particles. The Orowan bypassing [50-53] of the particle by the movement of dislocation increases the material's strength:

$$
\Delta \sigma_{0 R}=\frac{0.13 G b}{d_{p}\left(\sqrt[3]{\frac{1}{2}} V_{p}-1\right)} \ln \left(\frac{d_{p}}{2 b}\right)
$$

where $G$ is the shear modulus of the material, $b$ is Burger's vector, and $V_{p}$ is volume fraction, and $d_{p}$ is the diameter of the dispersed particle.

2. Thermal dislocation strengthening The difference in the thermal coefficient of matrix material and the reinforcement material develop a residual strain upon cooling from elevated temperatures, which increases the density of the dislocation in the matrix phase around the reinforcement particle. The increase in dislocation density $\rho_{\text {CTE }}$ was proposed by Arsenault and Shy [54] as:

$\rho_{\mathrm{CTE}}=\frac{12 \Delta \alpha \Delta \mathrm{TV}_{\mathrm{r}}}{\mathrm{bd}_{\mathrm{p}}\left(1-\mathrm{V}_{\mathrm{r}}\right)}$

where $\Delta \mathrm{T}$ is a difference between the processing and room temperature, $\Delta a$ is the difference in the coefficient of thermal expansion (CTE) between the matrix and reinforcement, $d_{p}$ is the particle size, $V_{r}$ is the reinforcement volume fraction, and $b$ is Burger's vector of the matrix. The dislocation density of the material depends upon the size and the volume of the reinforcement. It increases with increases in the volume fraction of the reinforcement particle; however, it decreases as the size of the reinforcement increases. The strengthening effect was formulated by Taylor [55, 56] relationship can be given as:

$$
\Delta \sigma_{\mathrm{CTE}}=\mathrm{kG}_{\mathrm{m}} \mathrm{b} \sqrt{\rho_{\mathrm{CTE}}}
$$

where $k$ is constant, and $G_{m}$ is the shear modulus of the matrix. Thus, it is found that maximum strength contribution can be obtained from the smallest particle size with the highest volume fraction.

3. Grain size strengthening The strength of the metal matrix composite (MMC) increases as the incorporation of the reinforcement particle in the matrix, which acts as a nucleation site. Thus, during solidification, particle stimulated nucleation takes place. This nucleation is followed by grain growth, which continues until the particle impedes the grain boundary movement [57]. The following expression, which shows the relationship between the particle size (d), the grain size of the matrix $(D)$, and the volume fraction of the particle $\left(V_{r}\right)$, is expressed as [51]:

$D=d\left(\frac{1-V_{r}}{V_{r}}\right)^{1 / 3}$

It can be seen from the equation that a decrease in the size of the particle grain size decreases. The Hall Petch strengthening can be given by [58]:

$\Delta \sigma_{\mathrm{b}}=\frac{\mathrm{k}_{\mathrm{y}}}{\mathrm{D} / 2}$

The above equation shows the yield strength as a function of particle volume fraction and size. The increase in the yield strength is attributed to the decrease in particle size and an increase in the volume fraction of the reinforcement. Thus, the smaller the grain size, the greater is the grain boundary density, which impedes the motion of the dislocation.

4. Strain gradient strengthening The non-uniform distribution of the reinforcement particle in the matrix creates a strain gradient in the material. The geometrically necessary dislocation (GND) generated around the reinforcement particle creates a strain mismatch particle and the surrounding matrix $[55,59]$ :

$\Delta \sigma=\mathrm{kG}_{\mathrm{m}} \mathrm{b} \sqrt{\rho_{\mathrm{GND}}}$

where $\rho_{\mathrm{GND}}$ is the GND density and is given by

$\rho_{\mathrm{GND}}=\frac{6 \mathrm{~V}_{\mathrm{r}}}{\mathrm{bd}_{\mathrm{p}}}$

Thus, it can be seen that with an increase in GND density, strengthening occurs. It increases with an increase in the volume fraction of the particle and decreases with the particle size.

5. Load transfer strengthening The strengthening mechanism associated during load transfer from the matrix to the reinforcement particle by Modified Shear Lag (MSL) theory is given by [60]:

$\sigma_{C y}=\sigma_{m y}\left[V_{r} \frac{S+2}{2}+V_{m}\right]$

where $\sigma_{\mathrm{Cy}}$ and $\sigma_{\mathrm{my}}$ are the yield strength of the composite and the matrix, respectively, $\mathrm{V}_{\mathrm{r}}$ and $\mathrm{V}_{\mathrm{m}}$ are reinforcement and matrix volume fraction, and $S$ is the 
mean aspect ratio of the reinforcement. The higher is the volume fraction of the reinforcement particle higher is the load transfer. Thus, the contribution of this strengthening mechanism is given as:

$$
\Delta \sigma_{l}=\frac{1}{2} \sigma_{m y} V_{r}
$$

where $\sigma_{l}$ is the increase in strength due to load transfer. The above five attributes are responsible for enhancing the mechanical properties of FGAMCs.

\section{Different ceramic reinforcement particles}

Table 1 lists the different ceramic reinforcement particles, can be used to obtain continuous FGAMCs, and improvement in various properties such as hardness, tensile strength, and wear characteristics can be investigated. Ceramics play a significant role in the characteristics of FGMs. There are varieties of ceramics available which has been used as reinforcement particles in the Functionally graded aluminum matrix composites. They could be divided broadly into three groups-(a) Commonly used, (b) Rarely used and, (c) Unacquainted reinforcement particles in the fabrication of FGAMCs through centrifugal casting technique. It has been observed that $\mathrm{SiC}, \mathrm{B}_{4} \mathrm{C}, \mathrm{Al}_{2} \mathrm{O}_{3}$,

Table 1 Different types of ceramics reinforcement particles

\begin{tabular}{lllc}
\hline Reinforcement & Density $\left(\mathrm{g} / \mathrm{cm}^{3}\right)$ & Reinforcement & Density $\left(\mathrm{g} / \mathrm{cm}^{3}\right)$ \\
\hline $\mathrm{SiC}$ & 3.21 & $\mathrm{TiS}_{2}$ & 3.22 \\
$\mathrm{~B}_{4} \mathrm{C}$ & 2.52 & $\mathrm{AlB}_{2}$ & 3.19 \\
$\mathrm{Al}_{2} \mathrm{O}_{3}$ & 3.95 & $\mathrm{WC}$ & 15.63 \\
$\mathrm{ZrO}_{2}$ & 5.68 & $\mathrm{TiN}$ & 5.4 \\
$\mathrm{AIN}$ & 3.26 & $\mathrm{BN}$ & 2.1 \\
$\mathrm{Si}_{3} \mathrm{~N}_{4}$ & 3.44 & $\mathrm{TiB}_{2}$ & 4.52 \\
$\mathrm{TiO}_{2}$ & 4.23 & $\mathrm{NbC}$ & 7.82 \\
$\mathrm{SiO}_{2}$ & 2.65 & $\mathrm{ZrN}$ & 7.09 \\
$\mathrm{TiC}$ & 4.93 & $\mathrm{ZrC}$ & 6.73 \\
\hline
\end{tabular}

$\mathrm{ZrO}_{2}, \mathrm{AlN}, \mathrm{Si}_{3} \mathrm{~N}_{4}, \mathrm{TiO}_{2}, \mathrm{SiO}_{2}, \mathrm{TiC}, \mathrm{TiS}_{2}, \mathrm{AlB}_{2}$, and WC are used as reinforcement particles with aluminum and its alloys matrix to produce FGMs. The properties of aluminum and its alloys possess low weight, high corrosion-resistant, high electrical, and thermal conductivity. The combination of metal and ceramic materials in a varying manner provides enhanced mechanical and wear properties. The density of ceramic reinforcement particles and matrix material with centrifugal speed are the key factors to obtain gradation in the FGMs [61, 62].

Based upon previous investigations by researchers, the effect of different types of ceramic reinforcement particles on the microstructure, mechanical and tribological behavior of functionally graded aluminum matrix composites prepared using ex-situ centrifugal casting technique has been reviewed and summarized in the following sections.

\subsection{Effect of rarely used reinforcement particles}

\subsubsection{Titanium carbide (TiC)}

Because of low density, high hardness, high wear resistance, good wettability, chemical stability, and excellent strength at high-temperature, Titanium carbide gained a prominent position amongst the other reinforcement particles [63-65]. Instead of having such good properties, very limited works on $\mathrm{TiC}$ reinforced FGAMC have been reported. Some of them are illustrated below.

Radhika and Raghu [52] conducted a study on FGAMC of aluminum LM25-10 wt\% TiC (with $50 \mu \mathrm{m}$ average particle size) reinforcement fabricated by ex-situ horizontal centrifugal casting. The processing of FGAMC involves adding reinforcement particles to the melt at a stir speed of $200 \mathrm{rpm}$. This mixed material was then poured into the preheated die rotating at $1200 \mathrm{rpm}$ to obtain the FGAMC. Figure 5 showed the microstructure of cast FGAMC; the investigation has shown segregation of about $35 \%$ of $\mathrm{TiC}$ particles at the outer zone due to centrifugal action, which decreases towards the inner region, approximately $4 \%$. Hardness testing revealed, highest hardness value at
Fig. 5 Microstructure images of outer at $1 \mathrm{~mm}$ and inner surface at $13 \mathrm{~mm}$ LM25-TiC FGAMC [52]
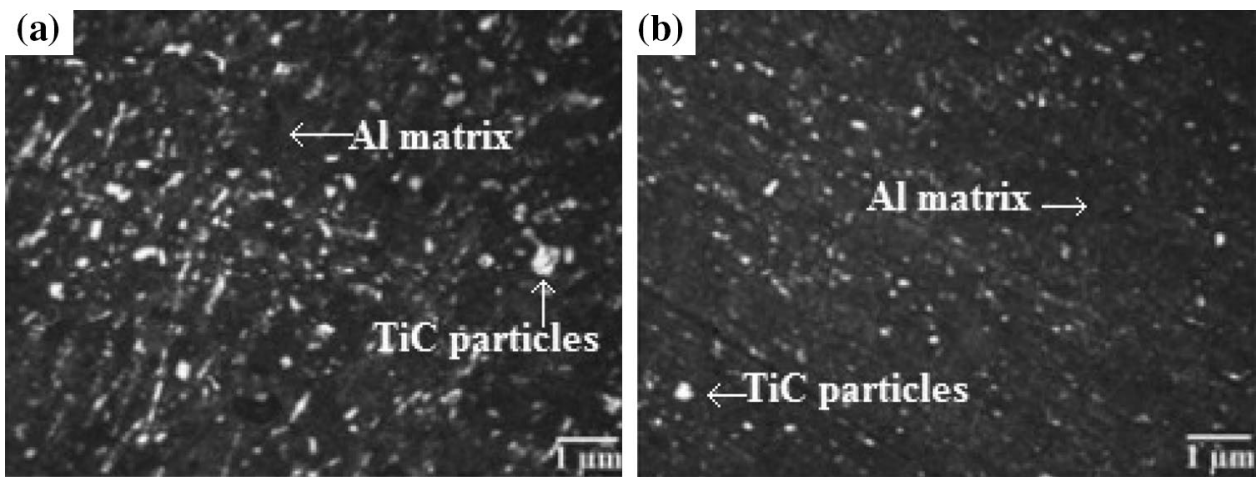
the outer surface $150 \mathrm{HV}$, and the minimum hardness was recorded as $102 \mathrm{HV}$ at the internal surface. The improvement in the hardness is attributed to the presence of reinforcement particles. Besides, the hard reinforcement particle distribution along the radial direction plays a vital role in improving the hardness.

Further, the tensile test result has shown the highest tensile strength value, $236 \mathrm{MPa}$, near the outer section, while the inner section showed a minimum value of $153 \mathrm{MPa}$. High tensile strength at the outer section is mainly due to the hindrance offered to the dislocations by the reinforcement particle. Figure 6 has shown the wear rate versus load and speed plot at distinct locations of FGAMC in which an improvement in wear resistance following the variation of reinforcement particles have been observed. This improvement in tribological characteristics is due to the non-removal of the reinforcement particles as the presence of the effective interfacial bond between matrix and hard reinforcement particles.

\subsubsection{Silicon nitride $\left(\mathrm{Si}_{3} \mathrm{~N}_{4}\right)$}

Silicon nitride possesses high hardness, mechanical strength, and good wear resistance when combined with the aluminum matrix; it also improves the characteristics of composites [66, 67].

The comparison between FGAMC (prepared through centrifugal casting) and the homogeneous composite (synthesized through gravity casting) of aluminum LM25 with 10 wt $\% \mathrm{Si}_{3} \mathrm{~N}_{4}$ (40 $\mu \mathrm{m}$ mean particle size) reinforcement particles has been reported by Radhika [68]. The FGAMC was prepared under $1250 \mathrm{rpm}$ by horizontal centrifugal casting. The micrography results showed the gradient particle distribution, highest at outer, transition at the

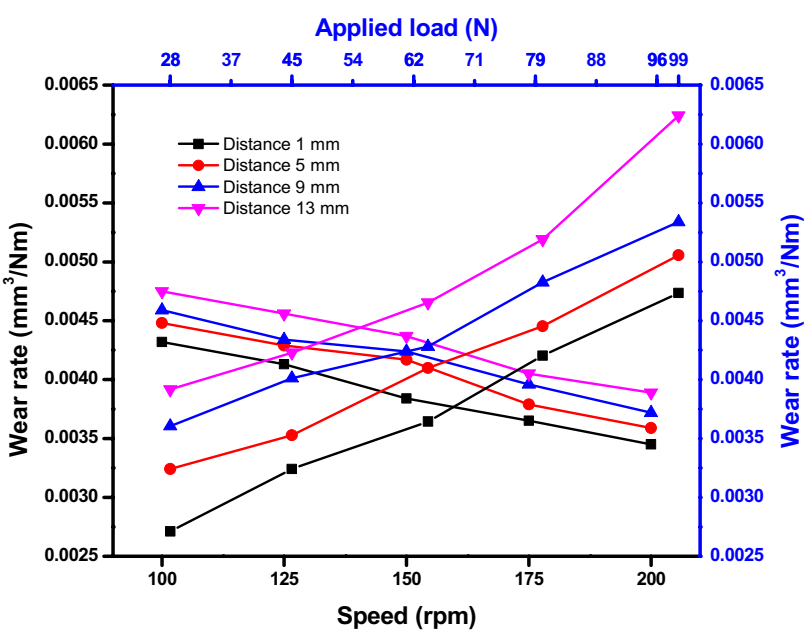

Fig. 6 Effect of load and speed on the wear rate of FGAMC at different locations [52] mid zone, and lowest distribution in the inner region of FGAMC, and the same can be seen in Fig. 7c-e. Similarly, Fig. $7 \mathrm{~b}$ showed the uniform distribution of $\mathrm{Si}_{3} \mathrm{~N}_{4}$ particles found in the case of the homogeneous composite. The variation in hardness and tensile strength of alloy, homogeneous composite, and different zones of FGMAC have presented in Fig. 8. In the same way, Fig. 9 described the superior wear resistance at the outer surface of FGAMC compared to homogeneous composite at different loads and speeds.

\subsubsection{Tungsten carbide (WC)}

Tungsten carbide, also known as wolframium carbide, is the highly-dense $\left(\rho=15.63 \mathrm{~g} / \mathrm{cm}^{3}\right)$ and hard ceramic particle. This particle affects the mechanical and tribological attributes substantially when used as reinforcement with the metal matrix.

Functionally graded aluminum matrix composite of LM25 alloy with 10 wt\%WC reinforcement was synthesized by Jojith and Radhika [53] using an ex-situ horizontal centrifugal casting process under $1000 \mathrm{rpm}$. The investigation included microstructure, mechanical, and wear characterization of FGAMC. Due to the centrifugal effect, the continuous variation of WC particles was seen in the microstructural examination. Mechanical characterization revealed the highest hardness $(126 \mathrm{HV})$, tensile $(156.65 \mathrm{MPa})$, and yield strength (83.67 MPa) value at the outer surface, followed by the mid and internal surface, which can be seen in Fig. 10. The presence of WC particles at the outer zone delayed the fracture during tensile testing resulting in improved tensile strength. The high tensile strength is due to the impedance that occurred during the movement of dislocation, causing strain hardening. It can be seen that the hardness is decreasing across the radial direction. It can be attributed to the resistance offered by the reinforcement particle to the indentation since the outer surface concentration is more than the inner region. Wear analysis was implemented at different locations of FGAMC at various loads (varied from 10 to $50 \mathrm{~N}$ ) and velocities (varied between 1 and $5 \mathrm{~m} / \mathrm{s}$ ). A decrement in wear resistance of outer surface with increasing applied load and an increment in the same with increasing sliding velocity was observed during wear examination. Also, Fig. 11 pointed out that the outer zone exhibited superior wear resistance than the middle and inner zone.

\subsubsection{Titanium diboride $\left(\mathrm{TiB}_{2}\right)$}

The influence of different reinforcement particles on various properties of FGAMCs has been characterized by Radhika and Raghu [69]. Four distinct functionally graded aluminum ( $\mathrm{Al}-12 \mathrm{Si}-\mathrm{Cu}$ alloy) matrix composites reinforced 

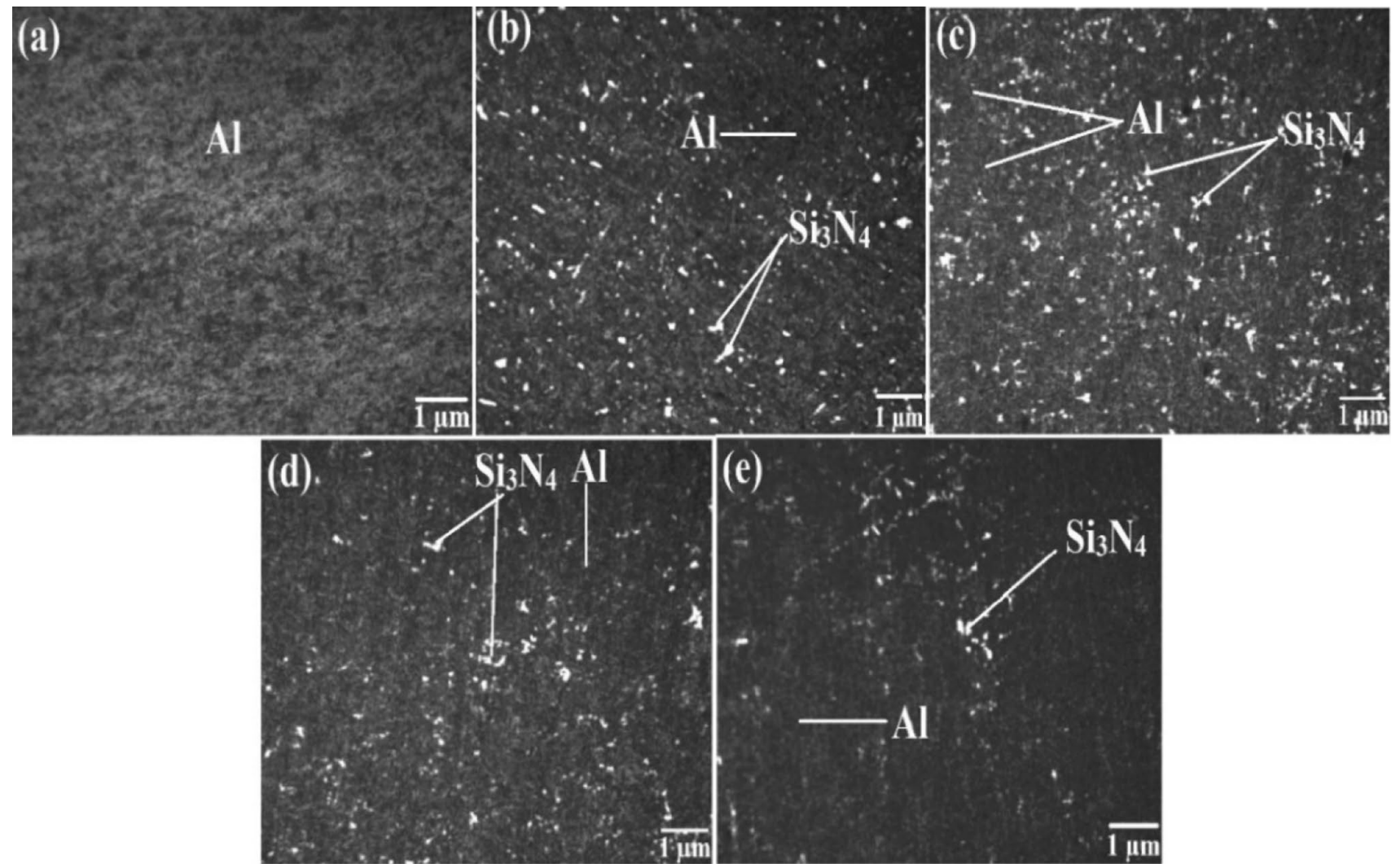

Fig. 7 Microstructure images of a unreinforced alloy $\mathbf{b}$ Homogeneous composite and c outer, $\mathbf{d}$ middle and e inner surface of LM25-10 wt\% $\mathrm{Si}_{3} \mathrm{~N}_{4}$ FGAMC [68]

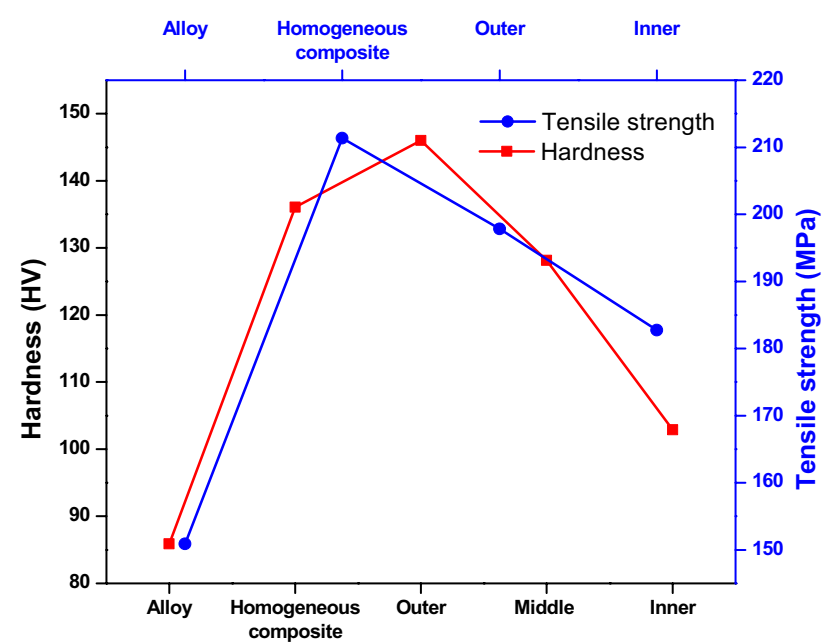

Fig. 8 Hardness and tensile strength variation of LM25 alloy, homogeneous composite and different zones of LM25-10 wt\% $\mathrm{Si}_{3} \mathrm{~N}_{4}$ FGAMC [68]

with distinct reinforcement particles, i.e., $\mathrm{B}_{4} \mathrm{C}, \mathrm{SiC}, \mathrm{Al}_{2} \mathrm{O}_{3}$, and $\mathrm{TiB}_{2}$ (12 wt\% each) with an average particle size of $10 \mu \mathrm{m}$. Hardness was evaluated at three distinct zones, while to measure tensile strength, outer and inner zones

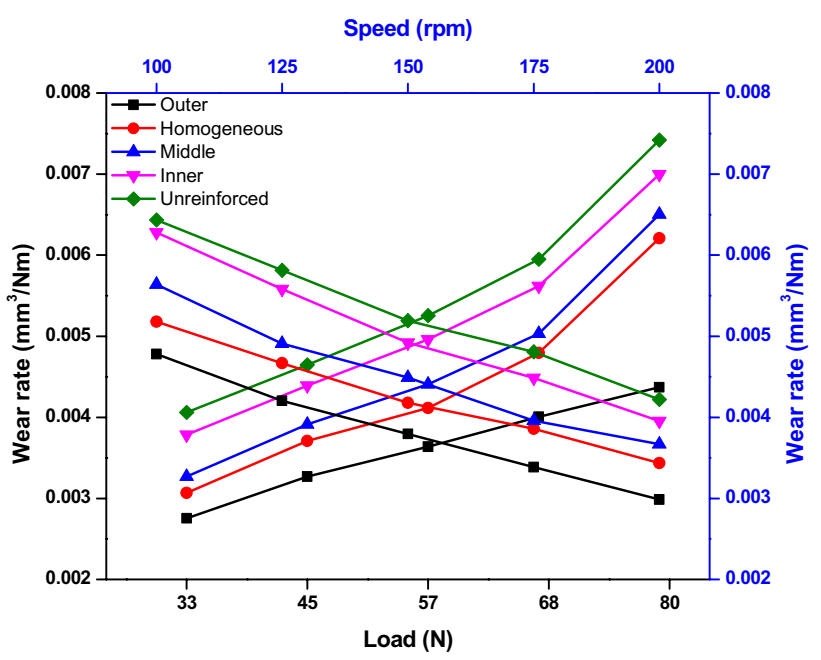

Fig. 9 Effect of load and speed on the wear rate of unreinforced alloy, homogeneous composite, and different zones of FGAMC [68]

were selected. Micrography results have shown segregation of all reinforcement particles at the outer region due to density difference and the centrifugal effect. The outer surface of $\mathrm{TiB}_{2}$ reinforced FGAMC showed improvement in

\section{SN Applied Sciences}




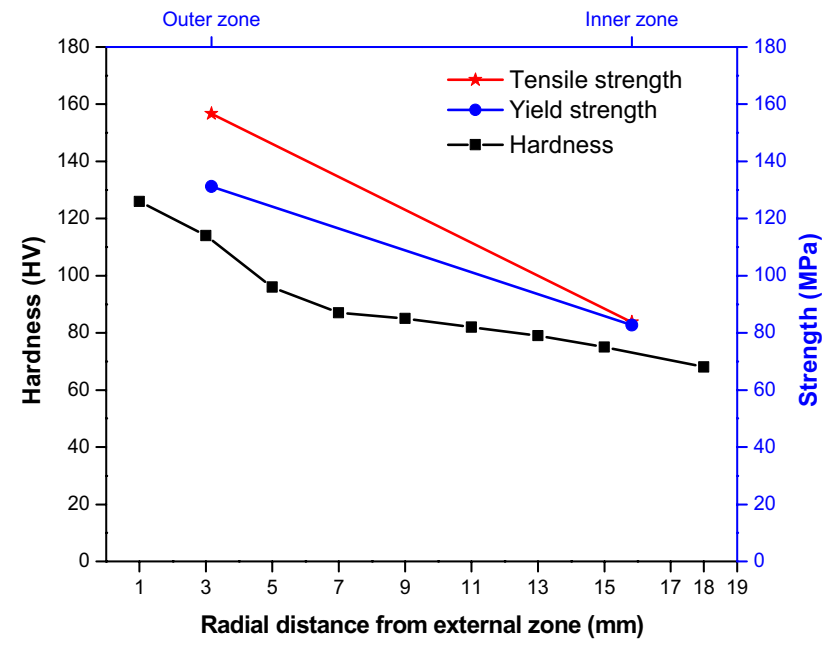

Fig. 10 Variation in hardness, tensile, and yield strength at different locations of LM25-10 wt\% WC FGAMC [53]

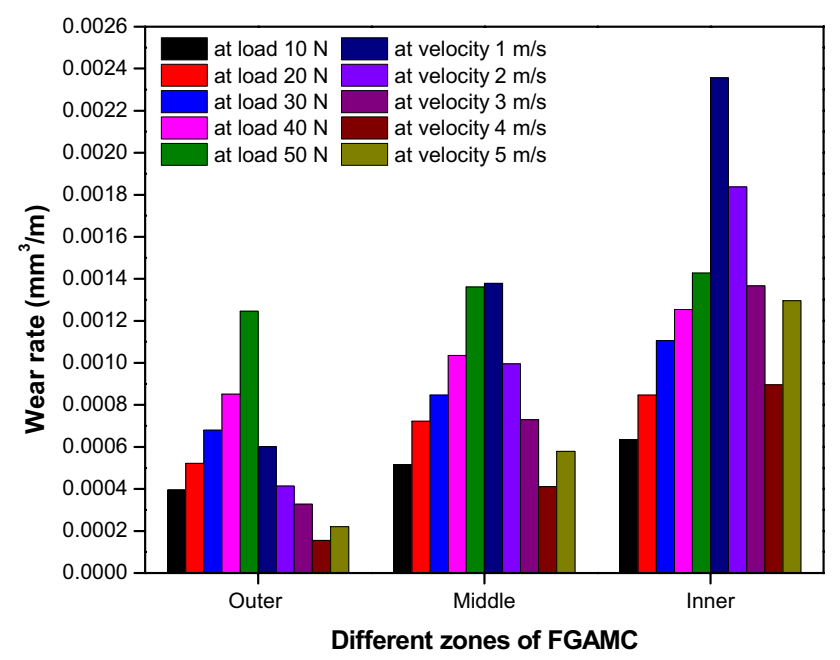

Fig. 11 Effect of load and velocity on the wear rate of distinct zones of LM25-10 wt\% WC FGAMC [53]

hardness by $25 \%, 11.11 \%$, and $8.11 \%$ and tensile strength by $7.47 \%, 3.81 \%$, and $2.74 \%$ than $\mathrm{B}_{4} \mathrm{C}, \mathrm{SiC}$, and $\mathrm{Al}_{2} \mathrm{O}_{3}$ FGAMC, respectively. Further, wear studies revealed that the outer circumference of the $\mathrm{TiB}_{2}$ reinforced FGAMC has shown wear rate in different loads as compared to the other FGMs presented in Fig. 12.

\subsubsection{Aluminum diboride $\left(\mathrm{A} \mathrm{B}_{2}\right)$}

$\mathrm{AlB}_{2}$ is the compound of aluminum and boron, which offers a significant improvement in mechanical properties when admixes with aluminum alloy [70]. To expose the behavior of $\mathrm{AlB}_{2}$ with the combination of aluminum and

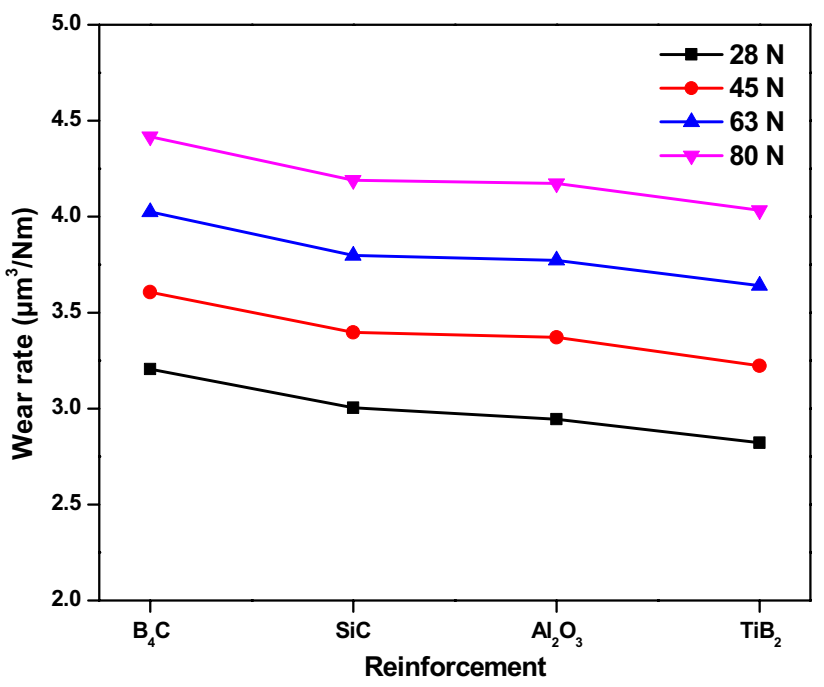

Fig. 12 Effect of different reinforcement particles on wear resistance of FGAMCs at different loads [69]

its alloys, it needs proper attention from the researcher community.

Radhika and Raghu [71] reported the wear characteristics of LM25 alloy with 10 wt $\%$ ( $45 \mu \mathrm{m}$ particle size) $\mathrm{AlB}_{2}$ reinforcement FGAMC manufactured through horizontal centrifugal casting method. Thereafter, this mixture was poured into the rotating die at $1200 \mathrm{rpm}$ to produce FGAMC. Microstructural analysis has confirmed the gradient distribution of particles categorizing into three different zones, increasing towards the outer from the inner region. The hardness test revealed the highest hardness value at the outer surface as $142 \mathrm{HV}$, while $105 \mathrm{HV}$ at the inner surface was recorded. Abrasive wear testing was performed at the external, middle, and internal zone under two different abrasive mediums, i.e., silica sand and alumina (average particle size $50 \mu \mathrm{m}$ for each). The shape and hardness of abrasive particles matters on abrasion behavior. In this case, alumina particles possess higher hardness with smooth curvy edges, while the silica sand has a little lower hardness with sharp angular edges. As presented in Fig. 13, the outer surface of FGAMC showed a minimum wear rate as compared to the mid and internal region, under both abrasion mediums and further concluded that the minimum wear rate was observed under the alumina abrasive medium because the smooth curvy edged shape produces less stress field as compared to the sharp angular edged silica sand.

Furthermore, extended investigations on the effect of three distinct reinforcement particle sizes on the characteristics of LM25 alloy were carried out by Radhika and Raghu [72]. Three LM25-10 wt\% AlB 2 FGAMCs with particle sizes 15,44 , and $74 \mu \mathrm{m}$ were synthesized through exsitu horizontal centrifugal casting. These homogeneous 


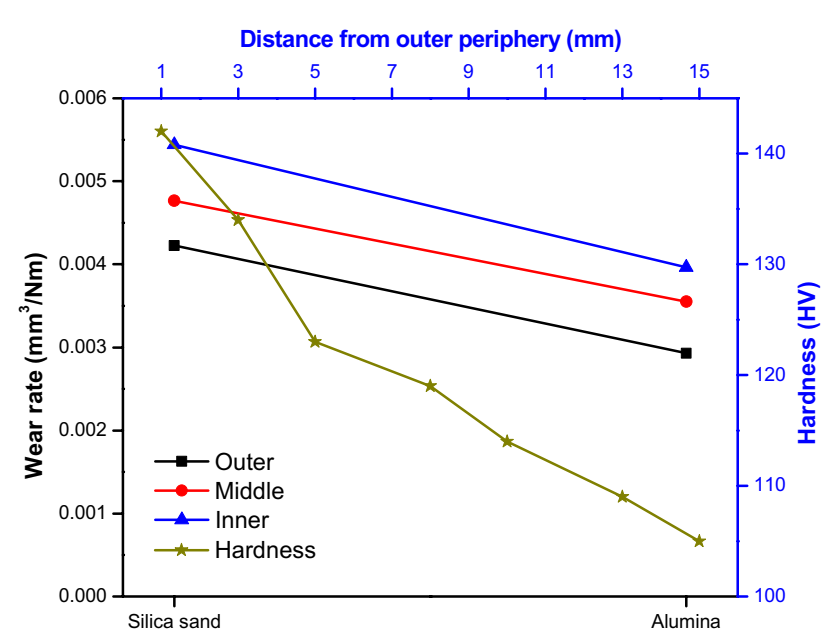

Fig. 13 Effect of abrasive medium on the wear rate of different zones and hardness variation of FGAMC along the radial direction from the outer periphery [71]

mixtures were poured separately into the rotating mold under $1220 \mathrm{rpm}$ to obtain three different FGAMC. In Fig. 14, large-sized $(75 \mu \mathrm{m})$ particle FGAMC has shown superior hardness, tensile strength, and minimal wear rate at the outer region, followed by $44 \mu \mathrm{m}$ FGAMC and $15 \mu \mathrm{m}$ FGAMC. The increase in tensile strength is due to the uniform distribution of smaller size particles across the region. The decrease in interparticle spacing between two reinforcement particles hinders the dislocation movement by bowing around the particles.

\subsubsection{Aluminum nitride (AIN) and silicon dioxide $\left(\mathrm{SiO}_{2}\right)$}

Aluminum Nitride is a low-density, high wear-resistant, high thermal, and low electrically conductive ceramic material. When combined with aluminum, it advances the mechanical properties of aluminum. Such qualities give

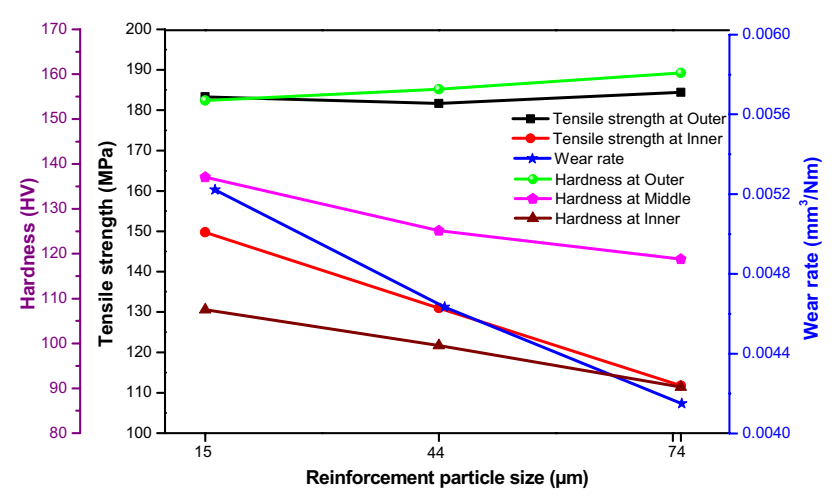

Fig. 14 Effect of different particle sizes on hardness, tensile strength and wear resistance of LM25-10 wt $\%$ AlB $_{2}$ FGAMC [72] rise to the AIN as the candidate reinforcement material [73, 74]. Similarly, the oxide of Silicon, also named Silicon dioxide having excellent thermal shock resistance, good abrasion resistance, and low electrical conductivity properties, which leads to the use of $\mathrm{SiO}_{2}$ as reinforcement materials with metal matrix composites for improved mechanical and wear characteristics [75].

The comparison between the abrasion wear performance of the LM25 alloy and its homogeneous composites and FGAMCs was explored by Radhika and Raghu [76]. Mean particle size $45 \mu \mathrm{m}$ of $\mathrm{AIN}$ and $\mathrm{SiO}_{2}(10 \mathrm{wt} \%$ each) were utilized to form homogeneous composites and FGAMCs. The alloy, homogeneous composites, and FGAMCs were prepared through traditional casting, stir casting, and ex-situ horizontal centrifugal casting techniques, respectively. Figure 15 showed the particle distribution variation from the inner to the outer surface, observed during microstructural analysis in both the FGAMCs. Hardness at the outer, middle, and inner surface of AIN FGAMC was found $5.2 \%$ and $5.6 \%$ higher and $4.85 \%$ lower than that of the respected surface of $\mathrm{SiO}_{2} \mathrm{FGAMC}$. Likewise, the external zone of Al/AIN FGAMC has 7.02\% higher hardness than the Al/AIN homogeneous composite, and the outer zone of $\mathrm{Al} / \mathrm{SiO}_{2} \mathrm{FGM}$ has shown $6.42 \%$ greater hardness value than the homogeneous composite of it. 192 and $182 \mathrm{MPa}$ was recorded as the highest tensile strength in the outer section of AIN FGAMC and $\mathrm{SiO}_{2}$ FGAMC, respectively, which were lower than the tensile strength of homogeneous composites. The wear test showed the highest wear resistance recorded in the outer section of AIN FGAMC amongst all materials described in Fig. 16; this was due to reinforcement particles in a high volume fraction at the outer section.

The effect of Rarely used reinforcement particles FGAMC, including different material and process variables, are organized under Table 2.

\subsection{Effect of commonly used ceramic reinforcement particles}

\subsubsection{Silicon carbide (SiC)}

Due to high thermal resistance, hardness, wear resistance, corrosion resistance properties, and easy availability with low cost, SiC ceramic particles become very popular and widely used reinforcement particles in composite materials production $[78,79]$. It is observed that generally, micron sizes of $\mathrm{SiC}$ particles were used as reinforcement in the aluminum matrix for improving the mechanical and wear characteristics of FGAMCs.

Fabrication and investigation on mechanical and wear behavior of $\mathrm{Al}-\mathrm{Cu}-\mathrm{Mg}$ alloy-5 wt\% SiC FGAMC through the ex-situ horizontal centrifugal casting method have 

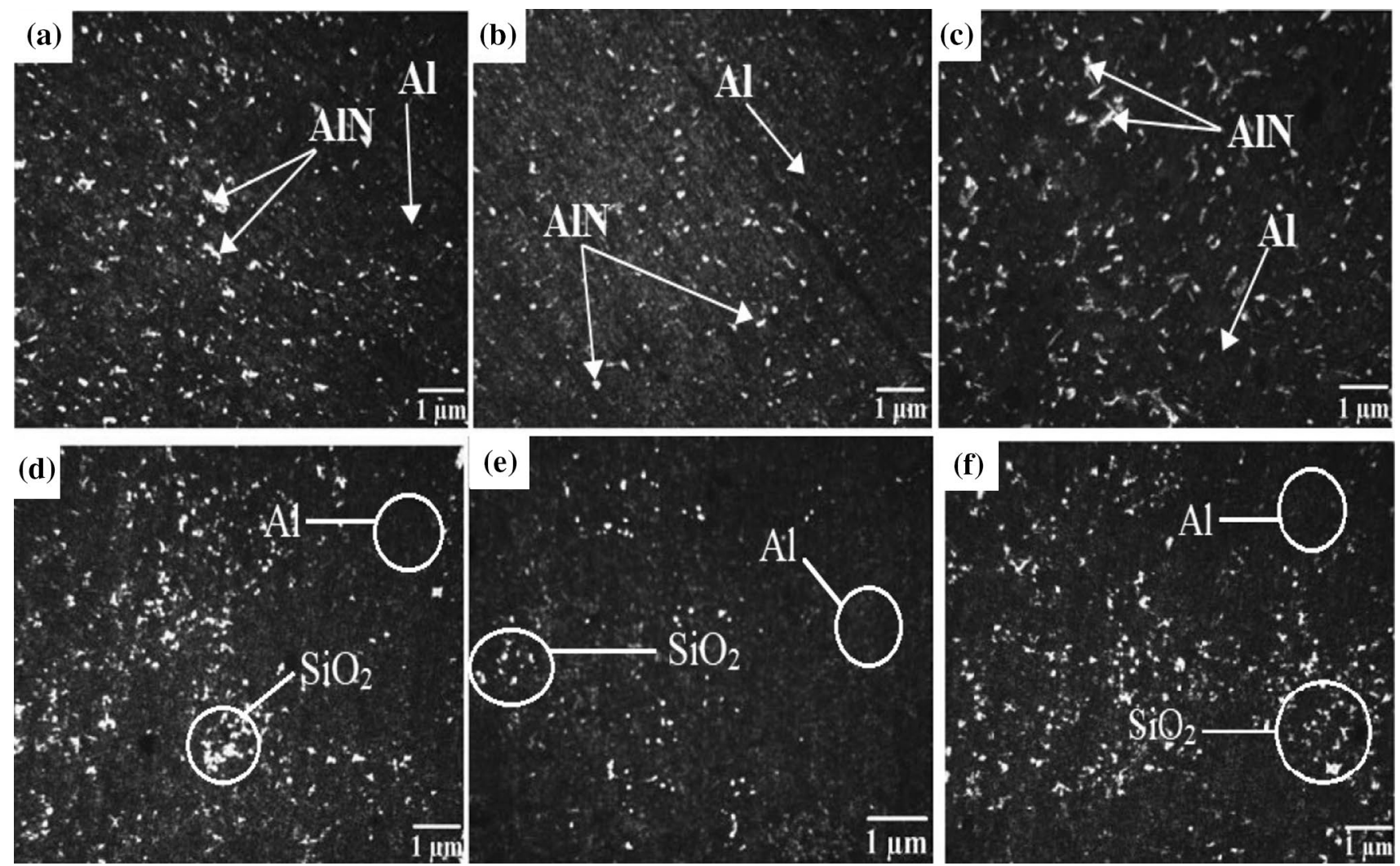

Fig. 15 Optical microstructure images of Al-AIN FGAMC a outer surface $\mathbf{b}$ Inner surface and $\mathbf{c}$ homogeneous $\mathrm{Al}-\mathrm{AIN}$ composite, and $\mathrm{Al}-\mathrm{SiO}{ }_{2}$ FGAMC $\mathbf{d}$ outer surface $\mathbf{e}$ inner surface and $\mathbf{f}$ Homogeneous $\mathrm{Al}-\mathrm{SiO}_{2}$ composite [76]
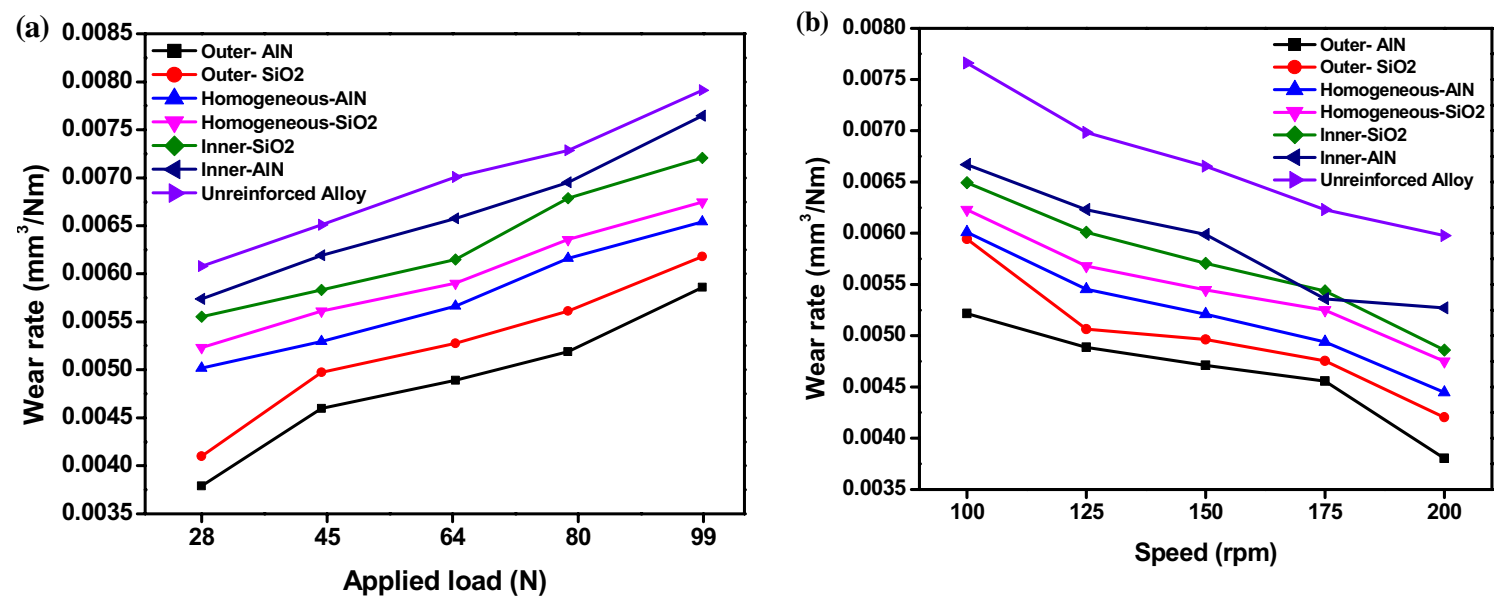

Fig. 16 Wear rate comparison at different loads and speeds of unreinforced alloy, different zones of AIN, SiO 2 FGAMCs and, homogeneous composites [76]

been carried out by Ömer Savaş et al. [80]. The processing of FGAMC included the pouring of the mixture of alloy and $\mathrm{SiC}$ particles at $750^{\circ} \mathrm{C}$ into a spinning mold under the centrifugal speed of $600 \mathrm{rpm}$. Microstructural observations have shown three distinct particle reinforced zones, i.e., exterior reinforced, particle-free, and interior reinforced in Fig. 17. Segregation of higher density $\mathrm{SiC}$ particles was found at the outer periphery, and a low concentration of $\mathrm{SiC}$ was observed at the inner zone, and the mid-zone is free from reinforcement particles. Figure 18 has shown 


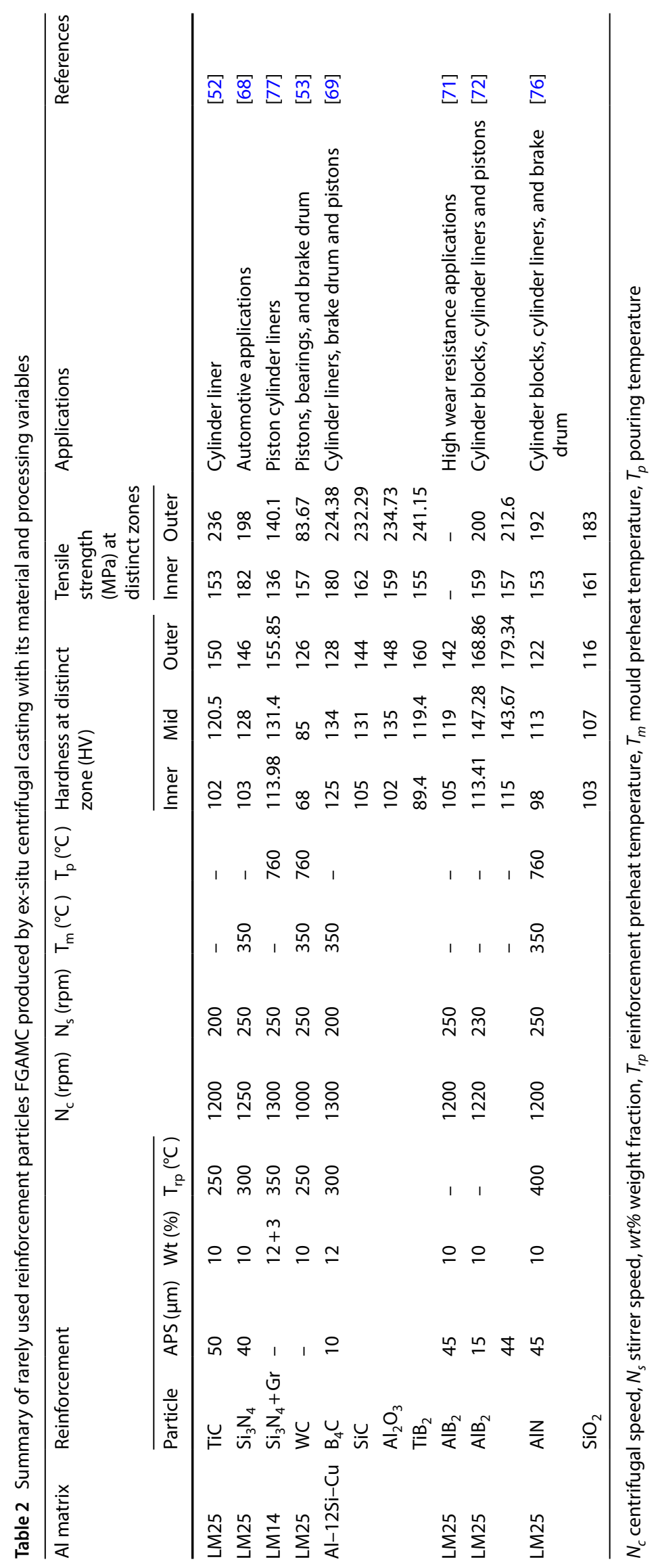



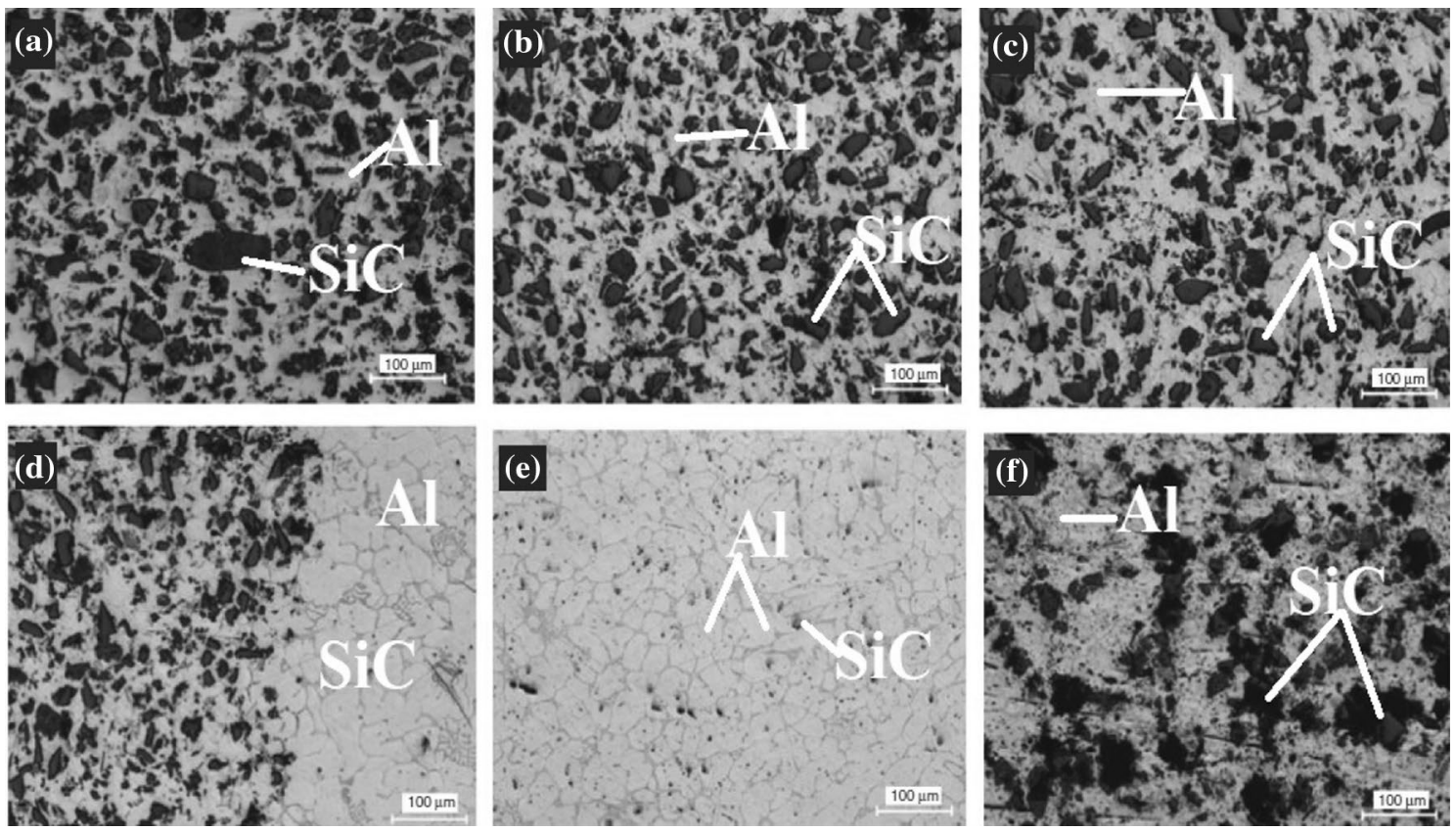

Fig. 17 Optical microstructure images different location of $\mathrm{Al}-\mathrm{Cu}-\mathrm{Mg}-5 \mathrm{wt} \% \mathrm{SiC}$ FGAMC from exterior to interior region across the thickness [80]

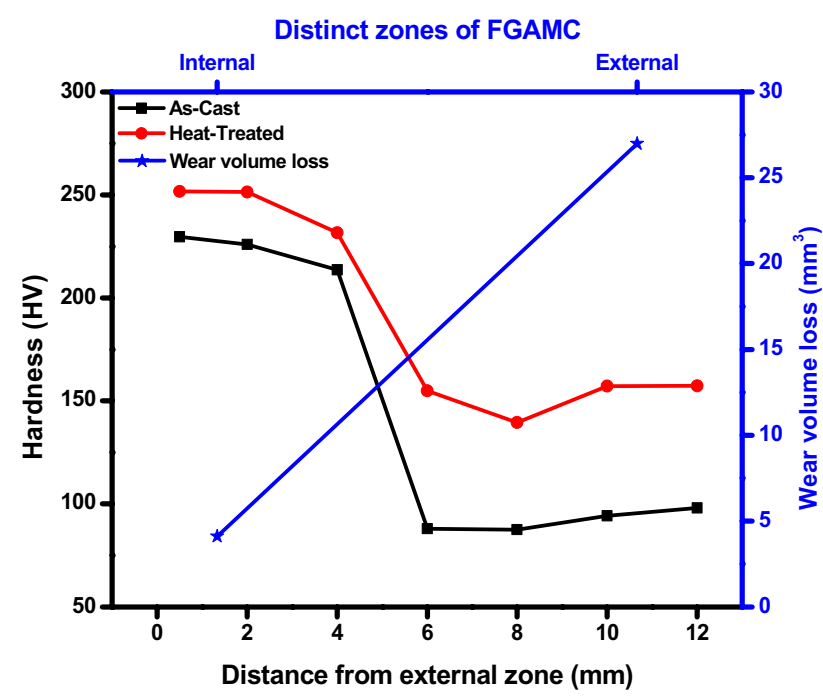

Fig. 18 Variation in hardness and wear rate of $\mathrm{Al}-\mathrm{Cu}-\mathrm{Mg}-5 \mathrm{wt} \%$ SiC FGAMC [80]

maximum hardness was recorded near the highly concentrated $\mathrm{SiC}$ zone and also at $50 \mathrm{~N}$ load, and, for $600 \mathrm{~m}$ sliding distance, the outer surface indicated the enhanced wear resistance than the inner zone.

Subsequently, Karun et al. [81] investigated and compared the microstructural, mechanical, and tribological characteristics of centrifugally casted A356 alloy and two FGAMC reinforced with different weight fractions (10 and $20 \mathrm{wt} \%$ ) of $23 \mu \mathrm{m}$ size $\mathrm{SiC}$ developed through the ex-situ vertical centrifugal casting technique followed by the stir casting. The microstructural study revealed a high concentration of $\mathrm{SiC}$ towards the outer surface due to higher density in both cases, but a higher concentration was observed in A356-20 wt\% SiC than A356-10 wt\% SiC. Centrifugal force influences the solidification rate at the inner zone of FGAMC. Low centrifugal force closer to the center of the mold causes porosities at the inner periphery due to the inclusion and agglomerations of low-density particles. Variation in cooling rates of material inside the mold causes an increase in grain sizes from the outer to the inner zone.

It can be seen from Fig. 19 that the highest hardness value in as-cast and heat-treated conditions have been measured for A356-20 wt\% SiC at the outer surface, and an increase in wear resistance found at the highly SiC concentrated zone. Due to the rapid solidification in the chill zone, formation takes place at the extreme outer region; subsequently, uneven distribution takes place, which leads to a lower hardness value. The increase in hardness of the heat-treated samples is due to the precipitation of reinforcement particles at the grain boundaries during solutionizing. Wear testing revealed the minimum wear rate at the higher $\mathrm{SiC}$ concentrated outer zone compared with the particle depleted inner surface of both FGAMC can be seen in Fig. 20.

Another study on FGAMC of aluminum alloy A359-20 wt\% SiC fabricated through centrifugal casting was reported by Rodríguez-Castro and team [82]. The effect 


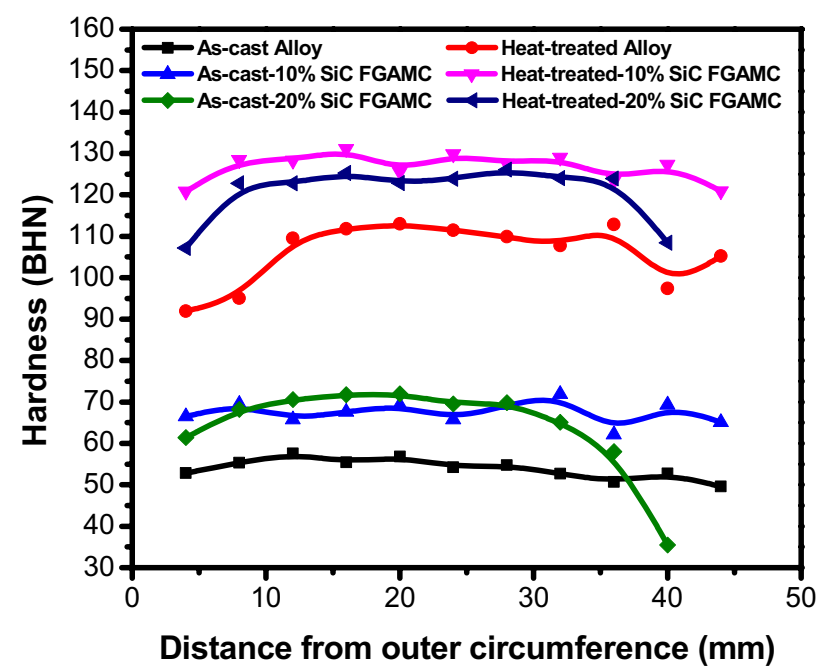

Fig. 19 Hardness plot for centrifugally casted A356 alloy, A356-10 wt $\%$ SiC, and A356-20 wt\% SiC FGAMCs in as-cast and heat-treated conditions [81]

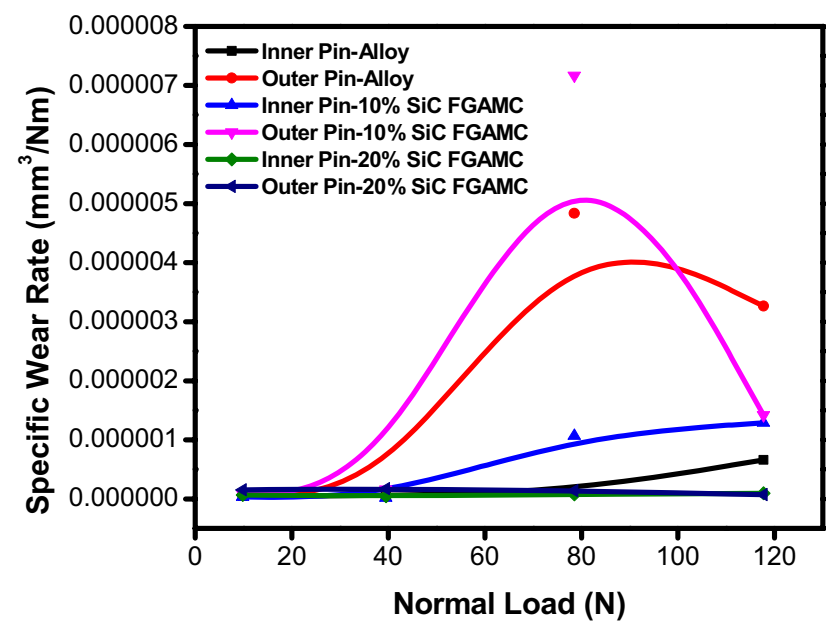

Fig. 20 Wear rate plot for centrifugally casted A356 alloy, A356-10 wt $\% \mathrm{SiC}$, and A356-20 wt\% SiC FGAMCs in as-cast and heat-treated conditions [81]

of mold rotation speed on microstructure and mechanical properties at different locations of FGAMC has been investigated. Better gradient formation of $\mathrm{SiC}$ reinforcement displayed along the radial direction of the sample fabricated under 1300 rpm than 700 rpm shown in Fig. 21. Also, significant variation in hardness and ultimate tensile strength was observed in $1300 \mathrm{rpm}$ FGAMC than $700 \mathrm{rpm}$ FGAMC. Functionally graded composite fabricated under $700 \mathrm{rpm}$ has shown significant improvement in yield strength with increasing $\mathrm{SiC}$ volume fraction.

Additionally, Vieira et al. [83] investigated the effect of mold rotation speeds on the dry sliding wear characteristics of centrifugally casted FGAMC of aluminum alloy (Al-10Si-4.5Cu-2Mg)/10 wt\% SiC (average particle size $37.8 \mu \mathrm{m}$ ). The FGMs were manufactured under two different speeds, i.e., 1500 and 2000 rpm, whereas unreinforced alloy was produced at $1500 \mathrm{rpm}$. The micrography test confirmed the sharp variation was observed in the FGAMC cast sample produced under the centrifugal speed of $2000 \mathrm{rpm}$, while $1500 \mathrm{rpm}$ FGAMC cast samples have shown a smooth distribution of $\mathrm{SiC}$ particles presented in Fig. 22. Minimum porosities were observed at the inner zone of FGAMC casting prepared using higher rpm. Figure 23 presented the improvement in hardness and wear characteristics that have been recorded from the outer to the inner of both FGAMC. The hardness was obtained highest for the $1500 \mathrm{rpm}$ FGAMC cast at the outer surface, whereas the inner zone of the 2000 rpm cast FGAMC has shown maximum hardness value. The tribological test revealed that the outer circumference of $1500 \mathrm{rpm}$ FGAMC cast had shown a minimum wear rate amongst all materials.

As discussed in this Sect. 2.2.1, the conclusion can be drawn that $\mathrm{SiC}$ particle size, weight fraction, and centrifugal speed play a significant role in determining the mechanical property of FGAMC. The difference in density of matrix and reinforcement particle and centrifugal speed plays a vital role in continuous gradient formation. Also, gradual refinement in grain size from the outer surface to the inner core of the cast was observed due to the solidification rate. Solidification rates are high near the inner side of the mold, and hence the outermost zone of the FGAMC cast, which is in contact with the inner wall of the mold, showed finer grain size than the inner zone. The different FGAMCs reinforced with $\mathrm{SiC}$ have produced under the range of centrifugal speed $600-2000 \mathrm{rpm}$, the mean particle size of range $12.89-500 \mu \mathrm{m}$ and weight fractions from 2.5 to $20 \mathrm{wt} \%$. Superior values of hardness and wear resistance were found near the outer region due to the presence of a higher concentration of $\mathrm{SiC}$ particles. Also, the improvement in tensile and compressive strength was observed in the outer section, along with the reduction in ductility.

\subsubsection{Aluminum oxide $\left(\mathrm{Al}_{2} \mathrm{O}_{3}\right)$}

Aluminum oxide (also called alumina) is another reinforcement material used widely after $\mathrm{SiC}$ to synthesize functionally graded aluminum matrix composite due to its adequate properties like high hardness, mechanical strength, high corrosion and wear resistance, high-temperature resistance, and thermal conductivity [84]. $\mathrm{Al}_{2} \mathrm{O}_{3}$ possesses such an excellent combination of properties, which attracts the researchers to use this material as reinforcement to the fabrication of FGAMCs. 
Fig. 21 Optical micro-images of Al-SiC FGAMC produced under $1300 \mathrm{rpm}$ centrifugal speed showing distribution of $\mathrm{SiC}$ in aluminum matrix from outer periphery towards inner at distance a $0.79 \mathrm{~mm}, 0.45$ vol\%, b $10.32 \mathrm{~mm}, 0.35$ vol\%, and c $26.19 \mathrm{~mm}, 0.23$ vol\% [82]
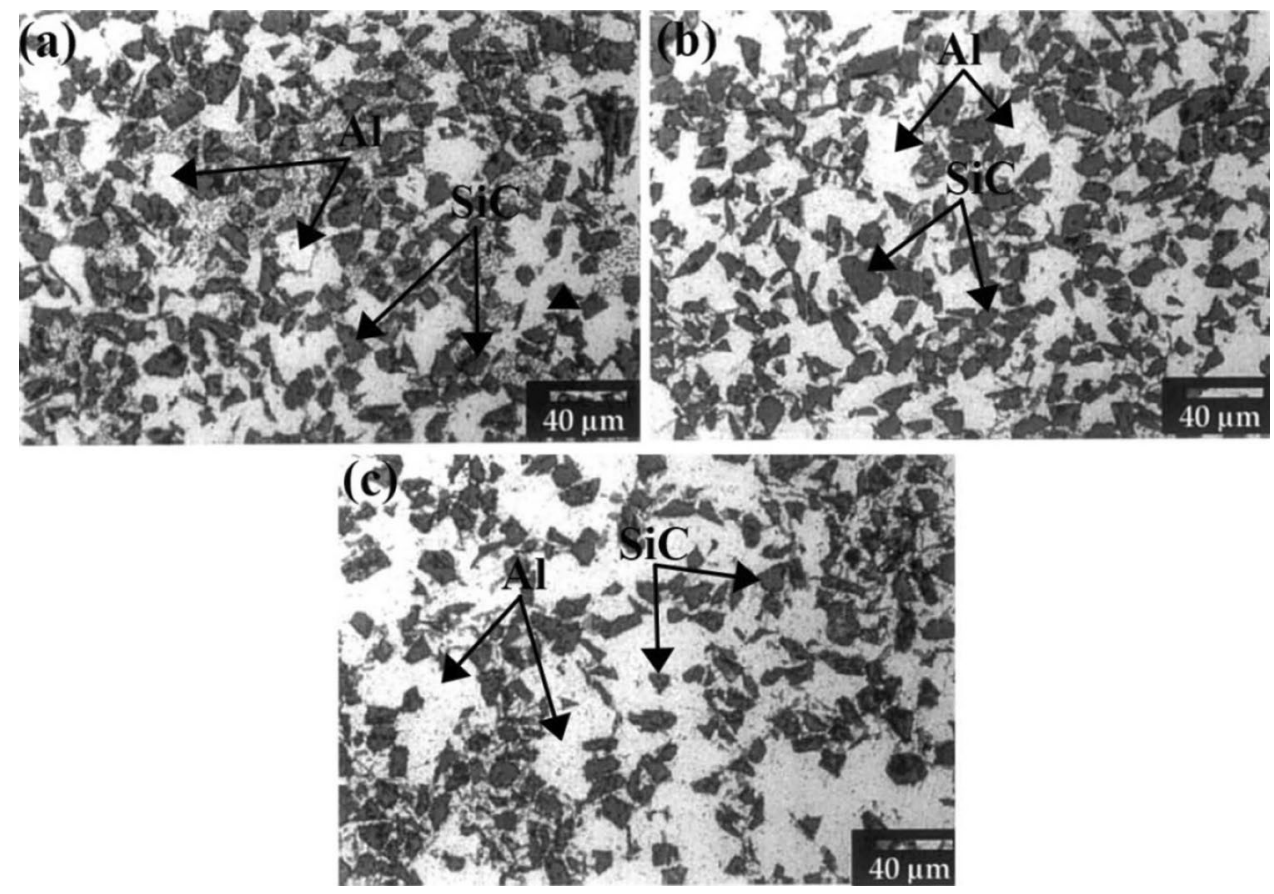

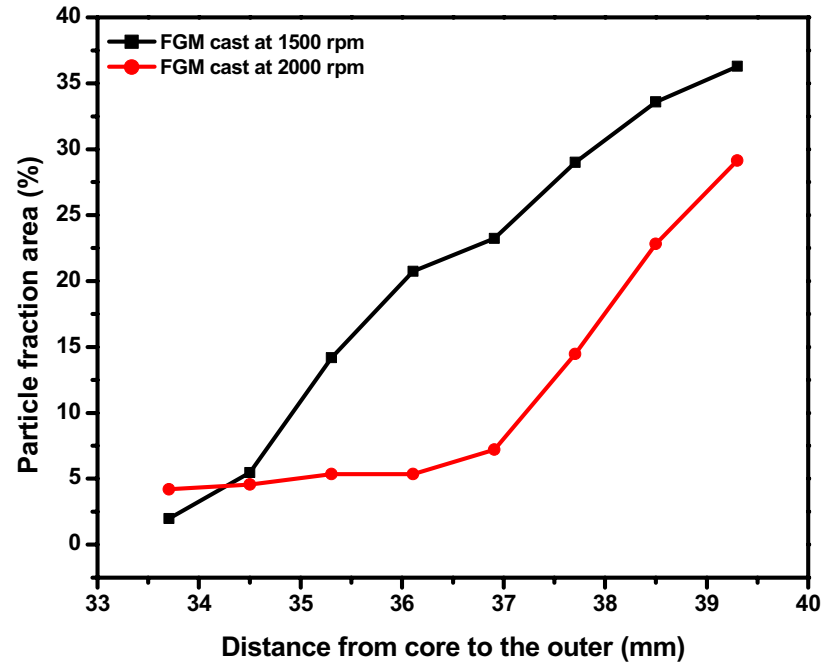

Fig. 22 Distribution of $\mathrm{SiC}$ particles along the radial direction of FGAMC $_{1500}$ and FGAMC $_{2000}$ [83]

Mer et al. [85] have used 10,15 , and $20 \mathrm{wt} \% \mathrm{Al}_{2} \mathrm{O}_{3}$ as reinforcement particles to synthesized pure aluminumbased FGAMC by low-speed centrifugal casting. The highest concentration of alumina has shown at the outer location as compared to the inner region. The hardness graph in Fig. 24 showed that the hardness of FGAMC increases by following the increase in the volume fraction of $\mathrm{Al}_{2} \mathrm{O}_{3}$ from the internal to the external surface. Maximum hardness was achieved near the external surface of all FGAMCs.

Furthermore, Junus and co-worker [86] worked on processing and characterizing $\mathrm{Al} 6061-\mathrm{Al}_{2} \mathrm{O}_{3}$ FGAMC with

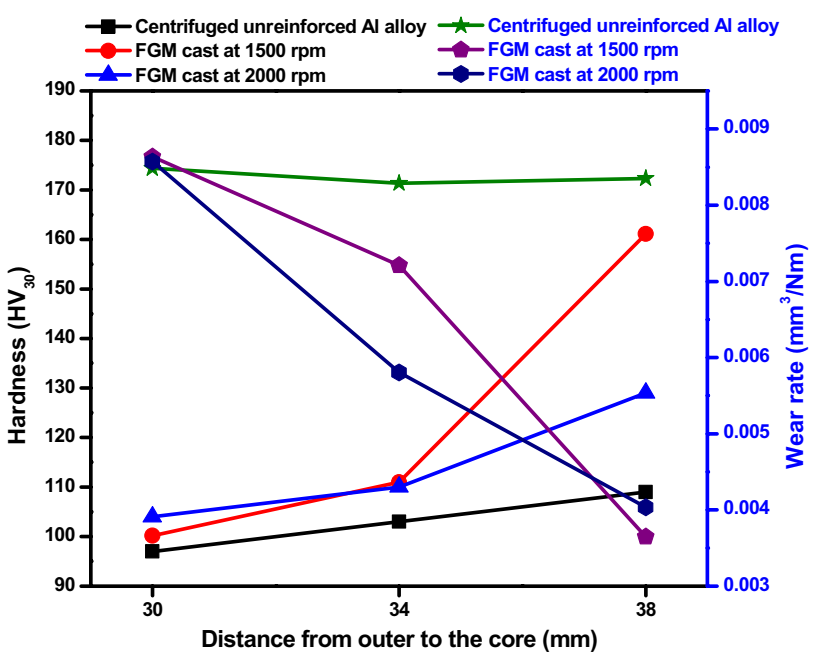

Fig. 23 Comparison between hardness and wear rate of unreinforced alloy, FGAMC $_{1500}$ and $\mathrm{FGAMC}_{2000}$ [83]

three different, 3,5, and 10 volume percentages of $\mathrm{Al}_{2} \mathrm{O}_{3}$ through three different processing methods, as-cast, stir casting, and the centrifugal casting process, respectively. They have found the centrifugally casted pipe possesses maximum hardness than that of stir and as-cast samples due to the centrifugal force that holds the particles in their remaining position, while in stir casting, the particles fall down due to gravity force causing inhomogeneous distribution.

After that, Prasad et al. [87] have synthesized and characterized Al6061 matrix FGAMC reinforced with $\mathrm{Al}_{2} \mathrm{O}_{3}$ 


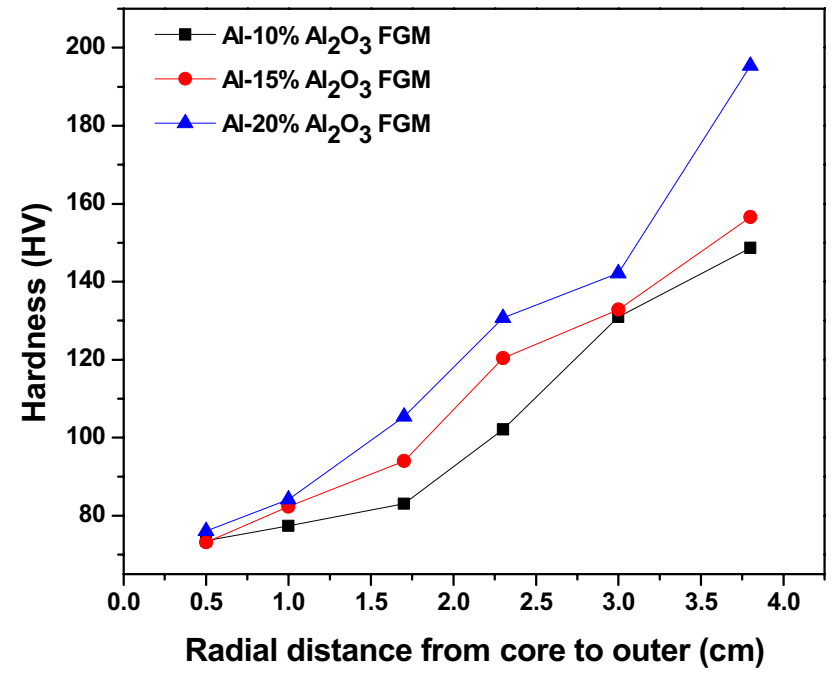

Fig. 24 Vickers hardness variations of different $\mathrm{Al}_{2} \mathrm{O}_{3}$ fractions FGAMC at different locations [85]

particles having a mean particle size of $30-50 \mu \mathrm{m} . \mathrm{Al}_{2} \mathrm{O}_{3}$ contents were varied from 0 to $20 \mathrm{wt} \%$ with an interval of $5 \%$. They have also seen the three different regions as outer reinforcement, particle-free mid, and inner reinforcement zone, as depicted by former research groups. Plot under Fig. 25 showed improved tensile strength and compressive strength accompanied by a decrease in ductility.

Subsequently, Saleh et al. [88] reported the effect of distinct weight fractions $(2.5,5$, and $10 \mathrm{wt} \%)$ of $\mathrm{Al}_{2} \mathrm{O}_{3}$ reinforcement particles (average particle size $16 \mu \mathrm{m}$ ) on pure aluminum FGAMC produced at different centrifugal speeds (as 800, 900, and $1000 \mathrm{rpm}$ ) through ex-situ horizontal centrifugal casting route. The presence of three distinct zones, high volume concentration, transition, and particle depleted zone of alumina particles at the outer, middle, and inner regions across the thickness, was observed in all three FGAMC in the microstructure analysis can be seen in Figs. 26 and 27. Likewise, Fig. 28 expressed the improvement in mechanical properties and wear behavior following the gradient observed in all FGAMCs. The hardness value was recorded maximum at the outer zone of the FGAMC produced with $10 \mathrm{wt} \%$ $\mathrm{Al}_{2} \mathrm{O}_{3}$ under centrifugal speed $1000 \mathrm{rpm}$. Maximum improved tensile strength and wear-resistant behavior were recorded at the outer circumference of $10 \mathrm{wt} \% \mathrm{Al}_{2} \mathrm{O}_{3}$ reinforced FGAMC produced under $1000 \mathrm{rpm}$ compared to the other FGAMCs. The increase in tensile and hardness of the FGAMC with an increase in rpm is attributed to the enhanced compaction caused by the centrifugal force in the outer region. Thus, it was concluded that an increase in weight fraction of $\mathrm{Al}_{2} \mathrm{O}_{3}$ reinforcement particles with an increase in centrifugal speed improved the mechanical properties of FGAMC.

The combination of aluminum and its alloy with reinforcement particle $\mathrm{Al}_{2} \mathrm{O}_{3}$ in a gradual manner advances the mechanical and wear properties in the continuous FGAMC fabricated under the centrifugal casting method. The density of the alumina particle $\left(3.95 \mathrm{~g} / \mathrm{cm}^{3}\right)$ is greater than that of the molten aluminum matrix $\left(2.7 \mathrm{~g} / \mathrm{cm}^{3}\right)$. Various FGAMCs using different weight fractions of $\mathrm{Al}_{2} \mathrm{O}_{3}$ ranging from 2.5 to $20 \mathrm{wt} \%$ have been produced under the centrifugal speed range from 200 to $1200 \mathrm{rpm}$, the average particle size of range 16-63 $\mu \mathrm{m}$. An increase in weight fraction of $\mathrm{Al}_{2} \mathrm{O}_{3}$ reinforcement particles in FGAMC
Fig. 25 Effect of different weight fractions of $\mathrm{Al}_{2} \mathrm{O}_{3}$ particles on tensile, compressive strength, and ductility of the FGAMC towards the outer zone [87]

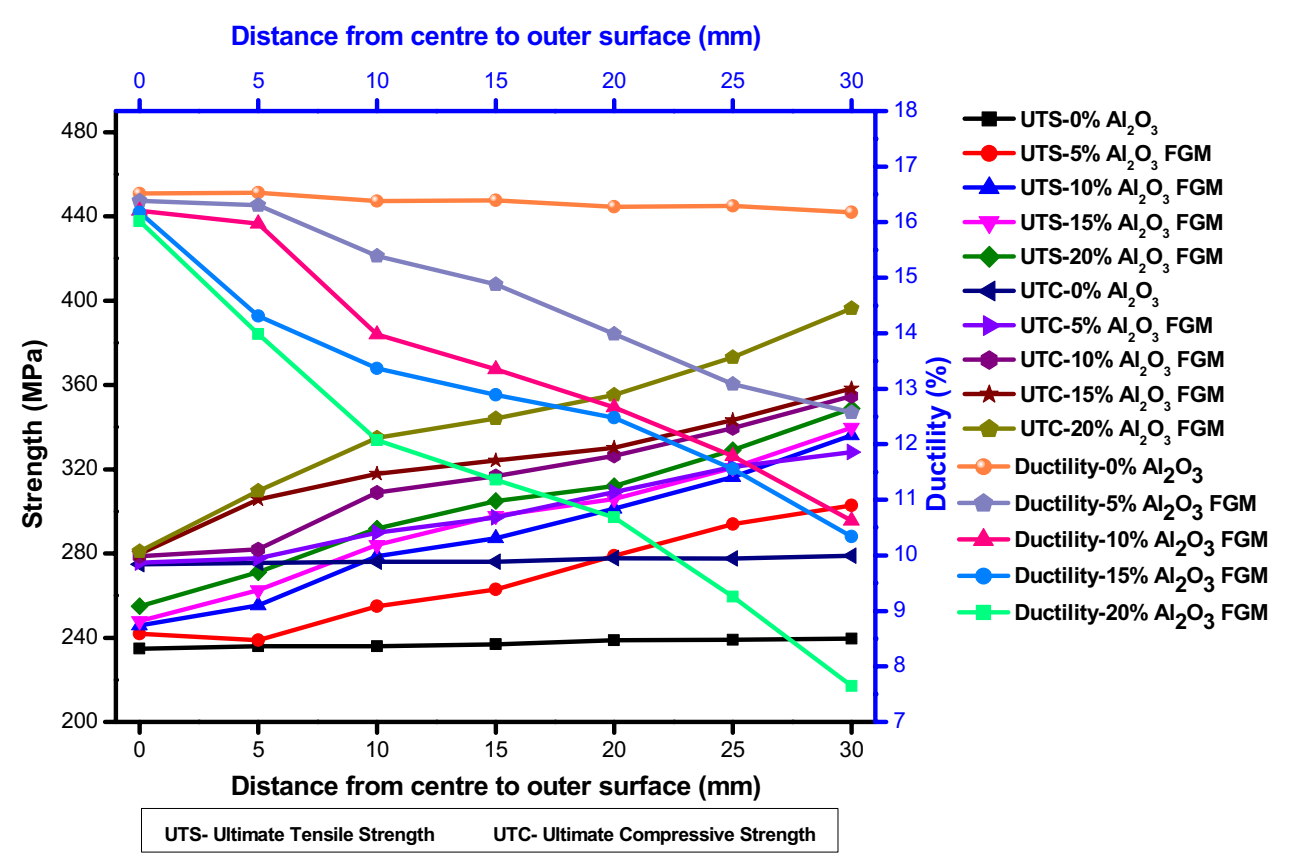


Fig. 26 Microstructure of pure Al-5 wt $\% \mathrm{Al}_{2} \mathrm{O}_{3}$ FGAMC from outer to inner periphery fabricated at 900 rpm [88]
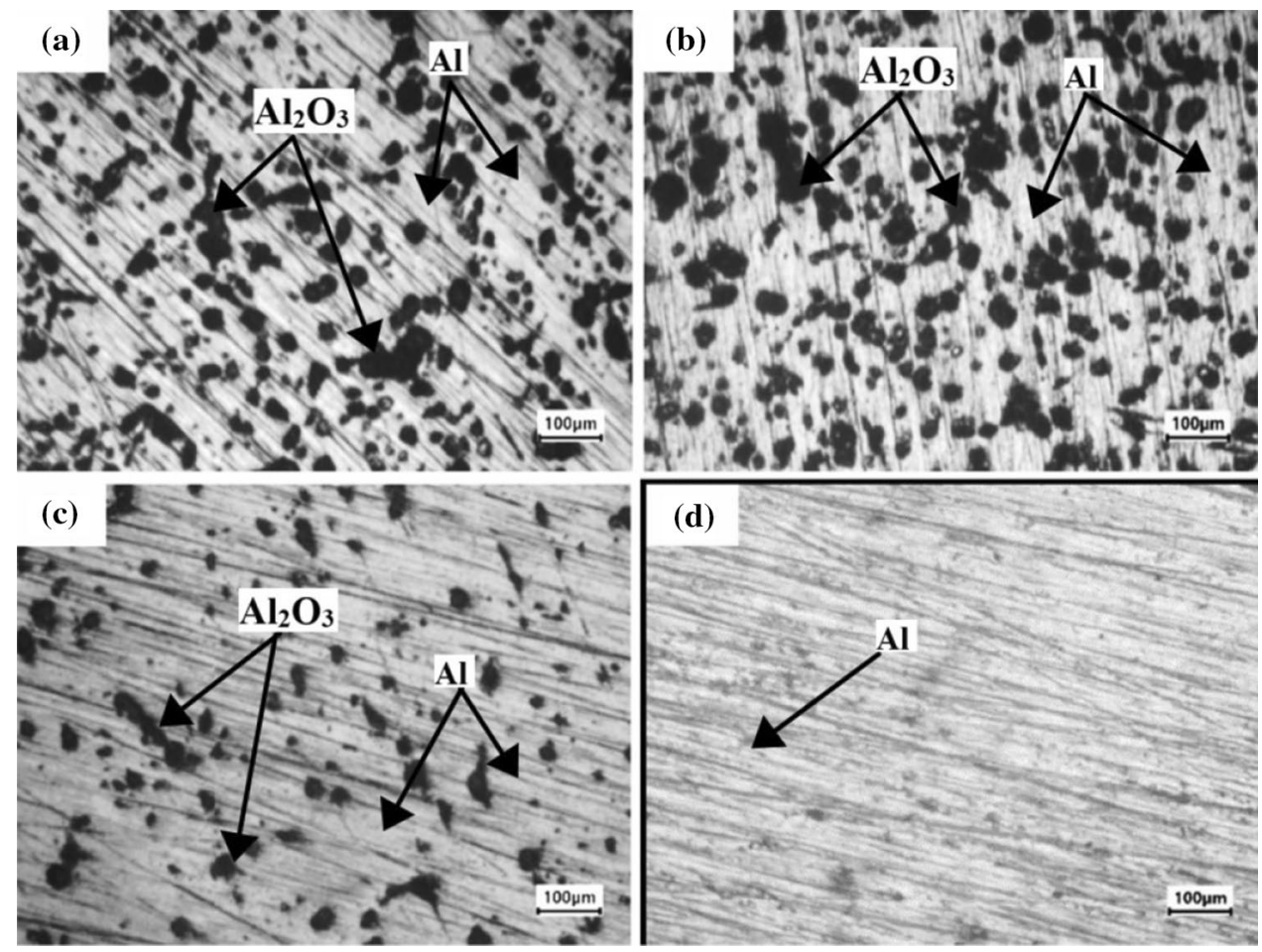

(d)

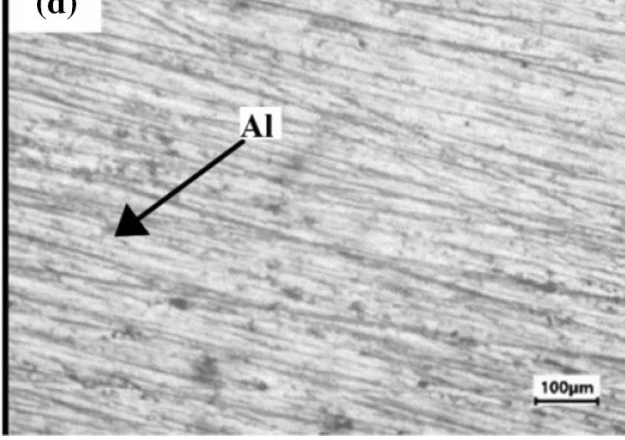

Fig. 27 Panoramic view of the microstructures of Pure Al-10 wt $\% \mathrm{Al}_{2} \mathrm{O}_{3}$ FGAMC tube along the radial direction fabricated at $1000 \mathrm{rpm}$ [88]

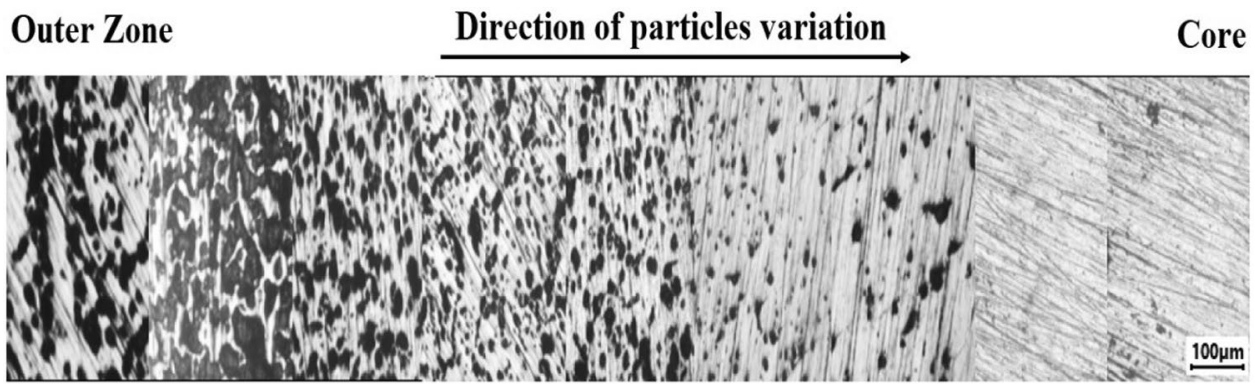

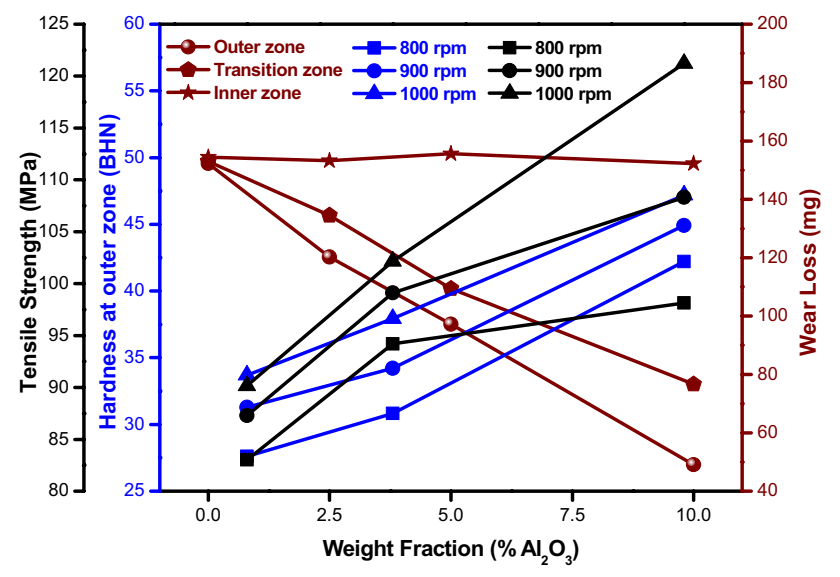

Fig. 28 Effect of distinct weight fractions of $\mathrm{Al}_{2} \mathrm{O}_{3}$ and centrifugal speed on hardness, tensile strength and wear rate of pure $\mathrm{Al}-\mathrm{Al}_{2} \mathrm{O}_{3}$ FGAMC [88] along with centrifugal speed has been shown an increase in mechanical properties like hardness, tensile strength, compressive strength, and tribological characteristics but a diminution in ductility.

\subsubsection{Boron carbide $\left(\mathrm{B}_{4} \mathrm{C}\right)$}

The proper combinations of aluminum and light density boron carbide in composite provides improved hardness and toughness with enhanced wear resistance in lightweight structures [89-92]. Due to poor wettability and agglomeration of $\mathrm{B}_{4} \mathrm{C}$ in aluminum matrix needs more attention from the researchers' community in the production of Al-B 4 C FGAMC through centrifugal casting $[93,94]$.

Rao and Co-workers [95] investigated the fabrication and evaluation of mechanical properties of centrifugally 
casted Aluminum 6061 with 10 wt $\% B_{4} C$ having $25 \mu \mathrm{m}$ mean particle size. The effect of centrifugal speed on the variation of $B_{4} C$ in aluminum 6061 alloy has also been reported. The microstructure image analysis confirmed the gradient formation along the radial direction, and the denser $\mathrm{B}_{4} \mathrm{C}$ reinforced the outer region was formed with increasing centrifugal force. Also, the hardness values were evaluated at different locations of FGAMC. Due to the presence of a high concentration of $\mathrm{B}_{4} \mathrm{C}$ particles at

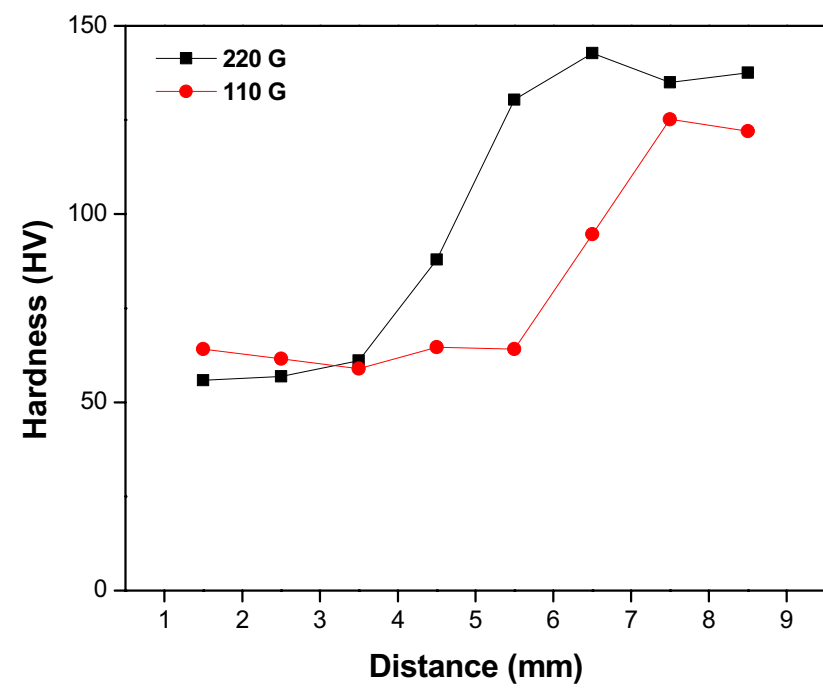

Fig. 29 Variation in hardness along the radial direction at different $\mathrm{G}$ values [95] the outer zone, an improvement in hardness, according to the gradation, was observed, and the same has been plotted in Fig. 29.

Afterward, Radhika and Raghu [96] have shown the effect of the addition of $10 \mathrm{wt} \% \mathrm{~B}_{4} \mathrm{C}$ particles (mean particle size 33-40 $\mu \mathrm{m}$ ) in Al-Si12Cu aluminum alloy FGAMC. This FGAMC has fabricated under 1000 rpm using a horizontal ex-situ centrifugal casting process. Figure 30 shows the gradual variation of $\mathrm{B}_{4} \mathrm{C}$ Particles from the outer to the inner periphery. Following the trend, the FGAMC cast is divided into three zones-particle rich outer zone, transition-middle zone, and particle depleted-inner zone. An increase in hardness as per the gradient present in the FGAMC was recorded during hardness testing. The effect of load, speed, and time on abrasive wear behavior of the FGAMC were studied. Enhancement in wear resistance was observed in the outer region during wear behavior study in all the conditions, as shown in Fig. 31. Wear resistance improved because the hard reinforcement particle performs as a load bearer element in the FGAMC that provides the formation and stability of adherent thick tribolayer to prevent wear loss.

Furthermore, another study on the fabrication and wear characterization FGAMC of aluminum alloy LM13 with 10 wt $\% \mathrm{~B}_{4} \mathrm{C}$ ( $25 \mu \mathrm{m}$ mean size) particle reinforcement using horizontal centrifugal casting was carried out by Muddamsetty and Radhika [97]. The heat treatment process was performed under various aging temperature to improve
Fig. 30 Microstructure of the Al-Si12Cu-10 wt $\% \mathrm{~B}_{4} \mathrm{C}$ functionally graded composite at different locations along radial direction a $3 \mathrm{~mm}, \mathbf{b} 9 \mathrm{~mm}$ and c $15 \mathrm{~mm}$ [96]
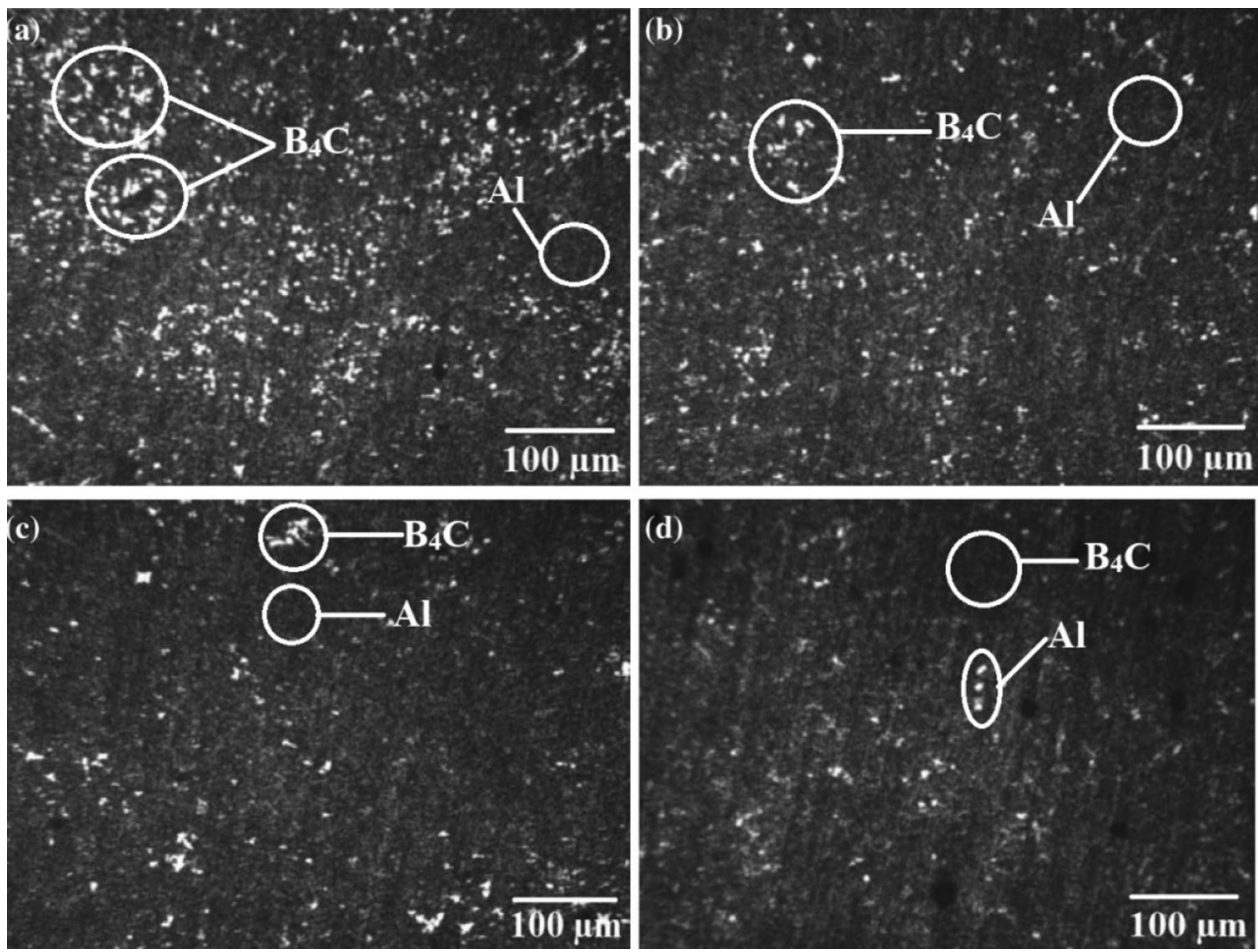


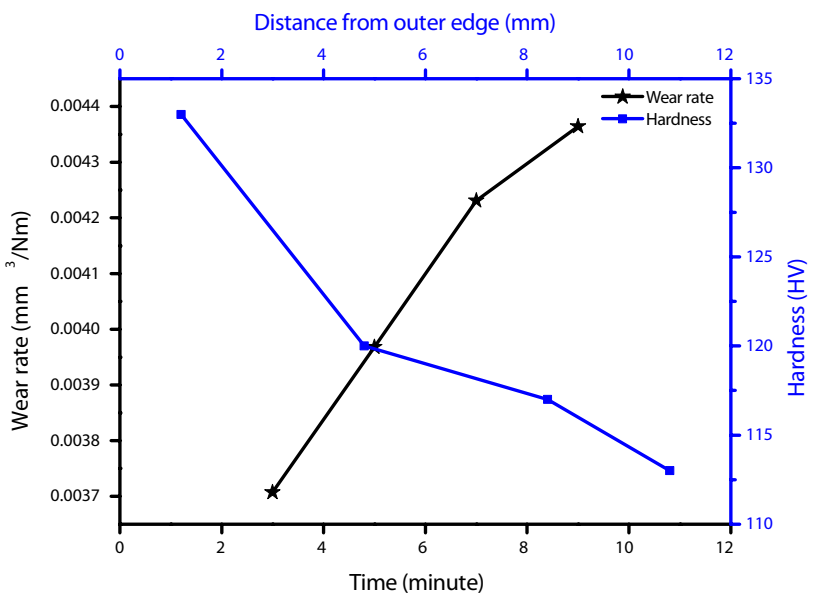

Fig. 31 A variation on hardness and wear rate of $\mathrm{Al}-\mathrm{Si} 12 \mathrm{Cu}-10 \mathrm{wt} \%$ $B_{4}$ C FGAMC [96]

the properties of FGAMC. Wear testings were performed on these heat-treated FGAMC specimens.

Improved wear resistance at the particle enriched outer surface can be seen in Fig. 32. Further, they performed Taguchi's optimization technique to analyze the effect of various factors such as load, aging temperature, and aging time on the adhesive tribological behavior of the LM13-10 wt\% $B_{4}$ C FGAMC. The optimized condition (i.e., minimum wear rate) was found at applied load $10 \mathrm{~N}$ with an aging temperature of $175^{\circ} \mathrm{C}$ and an aging time of $6 \mathrm{~h}$. The decrease in the wear rate with an increase in the aging temperature is due to the higher thermal diffusion, which causes the homogenous distribution of reinforcement particles inside the matrix. With further increase in temperature causes the reinforcement particle to segregate near the grain boundaries, which reduces the wear properties of the FGAMCs.

Radhika and co-workers [98] reported the comparison between horizontal centrifugally casted Functionally graded A359-10 wt $\% \mathrm{~B}_{4} \mathrm{C}$ and gravity cast A359-6 wt $\%$ $B_{4} C$. The wt $\%$ of $B_{4} C$ in gravity cast $M M C$ is equivalent to the outer zone of FGAMC. The outer zone of FGAMC and gravity cast $M M C$ has been compared under the as-cast and heat-treated conditions. The graph under Fig. 33 shown the microhardness and the tensile test results in which the outer zone of FGAMC has revealed the highest value of $161.8 \mathrm{HV}$ and $239 \mathrm{MPa}$ than gravity cast MMC. Similarly, the outer zone of FGAMC has shown a minimum wear rate than the MMC under all testing conditions during wear investigating.

Boron carbide influences the property of the aluminum matrix by improving its mechanical and wear characteristics. $\mathrm{B}_{4} \mathrm{C}$ has a lower density $\left(2.52 \mathrm{~g} / \mathrm{cm}^{3}\right)$ concerning other ceramic reinforced particles; however, it has a higher density than the melt aluminum matrix; therefore,

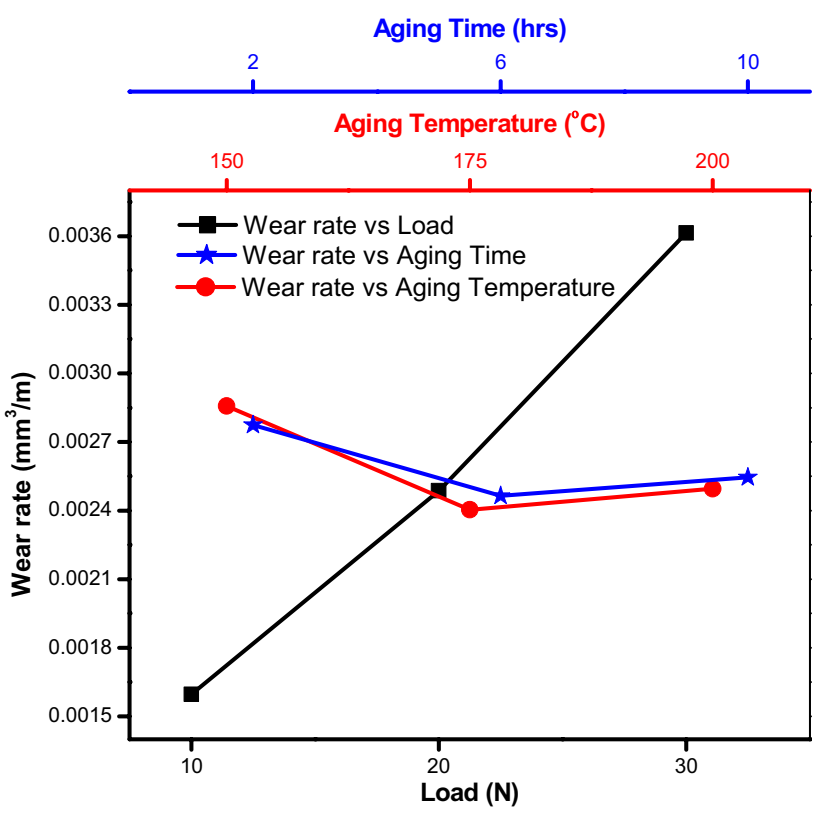

Fig. 32 Effect of load and heat treatment parameters on wear resistance of FGAMC [97]

$\mathrm{B}_{4} \mathrm{C}$ particles segregated at the outer wall with minimum porosities found at the inner wall of the FGAMC cast using centrifugal casting. It has been postulated that trapped gas bubbles during casting are responsible for porosities. Due to less density, these gas bubbles and some particles move towards the internal zone because of centrifugal force. Hence, the minimum amount of $\mathrm{B}_{4} \mathrm{C}$ particles were observed in the internal region of the FGAMC. A significant improvement in hardness, tensile strength, and wear characteristics were observed compared to virgin aluminum and its alloys. It has been observed that generally, centrifugal speed from 600 to $1500 \mathrm{rpm}$, with a mean particle size

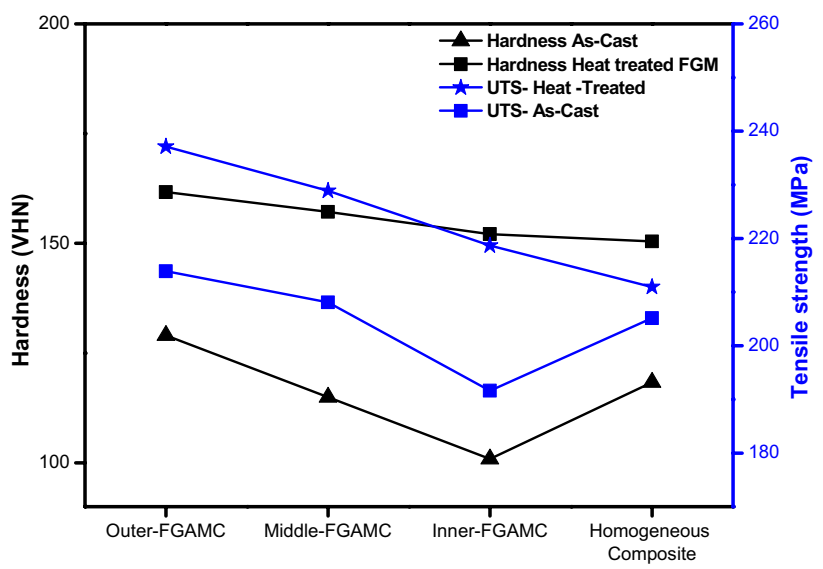

Fig. 33 Effect of heat treatment on hardness and tensile strength of FGAMC and homogeneous composites [98] 
range $10-40 \mu \mathrm{m}$ and up to weight fraction $10 \mathrm{wt} \%$ used for the synthesis of $\mathrm{B}_{4} \mathrm{C}$ reinforced FGAMC.

\subsubsection{Zirconium oxide $\left(\mathrm{ZrO}_{2}\right)$}

Zirconium Oxide (also called Zirconia) possesses excellent mechanical, thermal, and tribological properties such as high tensile strength, hardness, high fracture toughness, and corrosion and wear resistance [99]. It is widely used ceramics in the manufacturing of various engineering applications, such as refractories, cutting tools, structural opacifiers, and gas sensors [100].

Radhika and Raghu [101] produced FGAMC of Al-Si12Cu alloy with $10 \mathrm{wt} \% \mathrm{ZrO}_{2}$ (average particle size $50 \mu \mathrm{m}$ ) ceramic reinforcement through ex-situ horizontal centrifugal casting processing technique. Figure 34 illustrated the microstructural images showing a highly dense outer zone with $\mathrm{ZrO}_{2}$ particles decreasing towards the core region. An abrasive wear test was performed under varying load with fixed sliding speed. In all loading conditions, the $\mathrm{ZrO}_{2}$ particle rich outer surface has shown a minimum wear rate, and the same can be observed in Fig. 35.

Subsequently, Smrutirekha Sen and team [102] fabricated and investigated the $\mathrm{Al}-5 \% \mathrm{Si}$ alloy- $\mathrm{ZrO}_{2}$ reinforced FGAMC using ex-situ vertical centrifugal casting. The consequence of different centrifugal speeds (i.e., 300 , 400 , and $500 \mathrm{rpm}$ ) on hardness and tensile strength were investigated. Figure 36 showed that the highest hardness and tensile strength were measured for $500 \mathrm{rpm}$ casted sample, whereas $300 \mathrm{rpm}$ sample has shown the lowest hardness and tensile strength value. The hardness and tensile strength were improved due to the deposition of $\mathrm{ZrO}_{2}$ particles at the casted sample's outer periphery because of the increasing centrifugal effect. Hence the significant impact of centrifugal speed on mechanical properties was observed.

Recently, Jojith and Radhika have done a very interesting study [103]. They have fabricated and compared

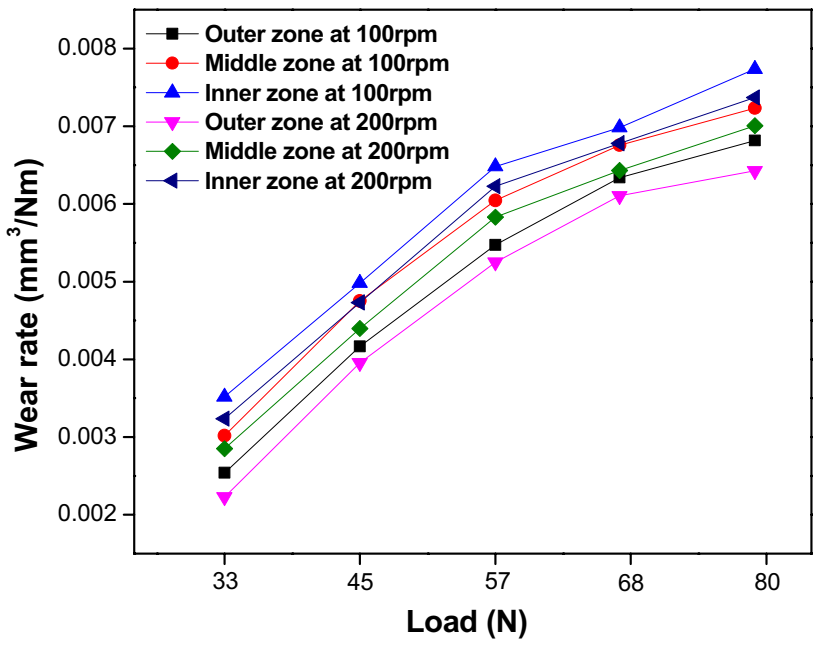

Fig. 35 Load versus wear rate plot of distinct surfaces of $\mathrm{Al}-10 \mathrm{wt} \%$ $\mathrm{ZrO}_{2}$ FGAMC [101]

three different $\mathrm{Al}-12 \mathrm{Si}-\mathrm{Cu}$ alloy FGAMCs with three different reinforcement particles $B_{4} C\left(\rho=2.52 \mathrm{~g} / \mathrm{cm}^{3}\right)$, SiC $\left(\rho=3.21 \mathrm{~g} / \mathrm{cm}^{3}\right)$ and $\mathrm{ZrO}_{2}\left(\rho=5.68 \mathrm{~g} / \mathrm{cm}^{3}\right)$ through ex-situ horizontal centrifugal casting technique. The particle sizes were chosen as $20 \mu \mathrm{m}$ for $\mathrm{B}_{4} \mathrm{C}$ and $\mathrm{ZrO}_{2}$, and $10 \mu \mathrm{m}$ for $\mathrm{SiC}$ particles, and $\mathrm{Al} / \mathrm{ZrO}_{2} \mathrm{FGAMC}$ has shown the highest density value amongst the $\mathrm{Al} / \mathrm{SiC}$ and $\mathrm{Al} / \mathrm{B}_{4} \mathrm{C}$ FGAMCs. Also, the enhanced density of FGAMC has been observed compared to the density of aluminum alloy. The microstructure images of all fabricated FGAMCs have confirmed the gradient formation along the radial direction following the density differences of aluminum matrix and reinforcements with centrifugal effect. Superior mechanical and tribological properties in the external region of $\mathrm{ZrO}_{2}$ reinforced FGAMC has been recorded and can be observed in Fig. 37.

$\mathrm{ZrO}_{2}$ affects and improves the characteristics of aluminum and its alloys when mixed in the proper ratio. Different aluminum alloy reinforced with $\mathrm{ZrO}_{2}$ was
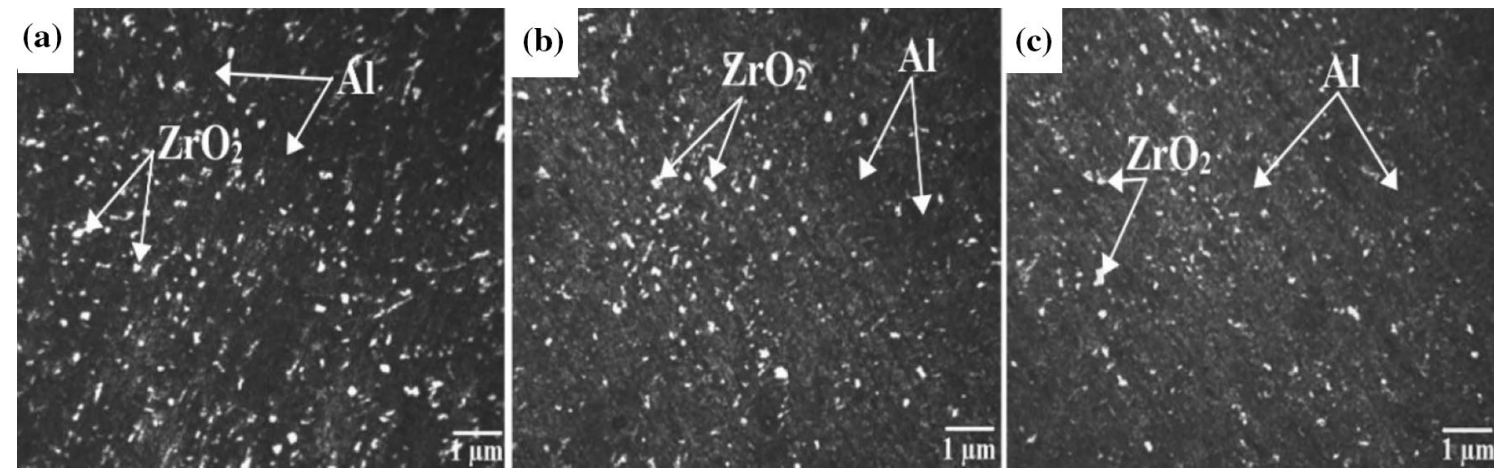

Fig. 34 Microstructures of the FGAMC a particle rich outer zone, $\mathbf{b}$ middle zone with particle transition, and $\mathbf{c}$ particle depleted inner zone [101] 


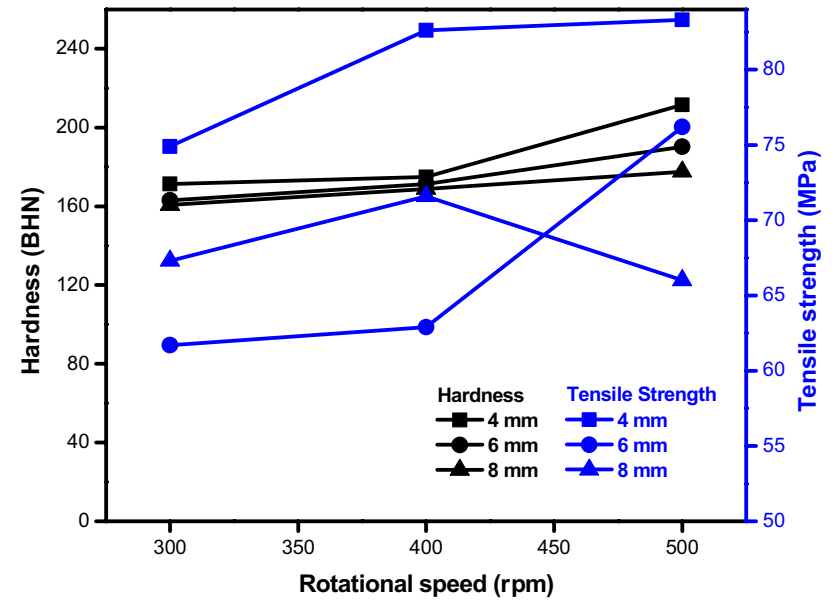

Fig. 36 Effect of centrifugal speed on hardness and tensile strength of $\mathrm{ZrO}_{2}$ reinforced FGAMC [102]

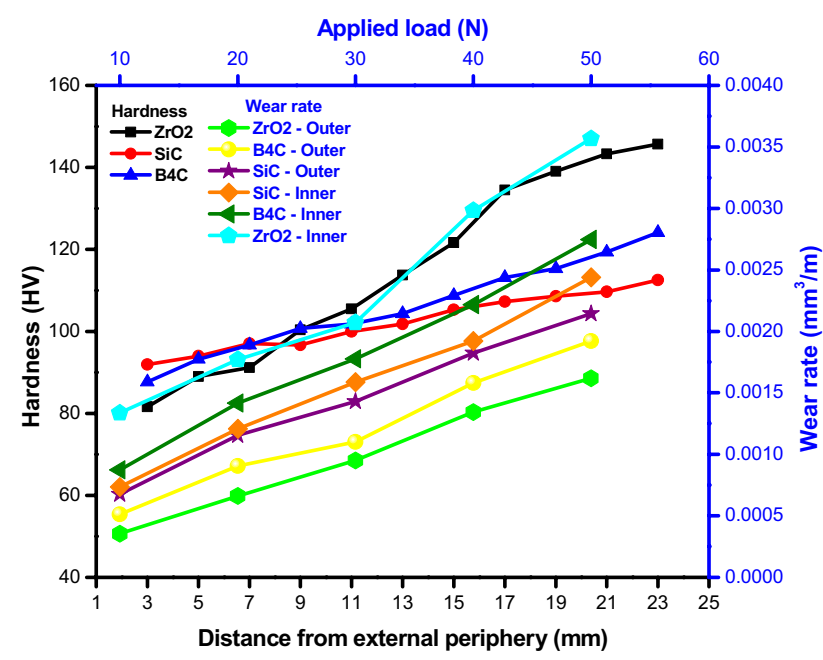

Fig. 37 Hardness and wear rate variation of different FGAMCs [103]

investigated. The density of the zirconium oxide is $5.68 \mathrm{~g} /$ $\mathrm{cm}^{3}$, which is greater than the density of the aluminum matrix. Thus, the properties were found more near the external section of the FGAMC cast. The process and materials parameters during fabrication also have a substantial impact on property enhancement. The increase in centrifugal speed confirms the increase in mechanical and tribological characteristics. The range of centrifugal speed used on the above reports varies from 300 to $1500 \mathrm{rpm}$, particle size ranges from 20 to $50 \mu \mathrm{m}$, and weight fraction of $\mathrm{ZrO}_{2}$ reinforcement used was $10-15 \mathrm{wt} \%$.

The effect of Commonly used reinforcement particles FGAMC, including different material and process variables, are organized under Table 3.

\section{Optimization of various parameters for mechanical properties improvement}

In order to achieve the optimum properties for the FGAMC, a linear regression model has been used. The parameters involved in the processing of FGAMC using the ex-situ centrifugal method listed in Tables 2 and 3 were optimized using linear regression analysis to maximize the hardness and tensile strength with the help of Minitab19 software. In this analysis, only the properties at the outer sections are considered, as in this section, mechanical properties were found maximum than inner and mid-zone. The developed regression model for hardness and tensile strength are given in Eqs. (17) and (18), respectively.

$$
\begin{aligned}
\text { Hardness }= & 633-0.100 A P S+7.00 \mathrm{Wt}-0.0205 \mathrm{~N}_{c} \\
& -0.384 \mathrm{~T}_{\mathrm{m}}-0.538 \mathrm{~T}_{\text {pour }}
\end{aligned}
$$

Tensile strength $=-393+2.65 \mathrm{APS}+2.95 \mathrm{Wt}-0.460 \mathrm{~N}_{\mathrm{c}}$

$$
-2.15 \mathrm{~T}_{\mathrm{m}}+2.30 \mathrm{~T}_{\text {pour }}
$$

where, APS — average particle size, $\mathrm{Wt}$ - weight fraction of reinforcement particles, $\mathrm{N}_{\mathrm{c}}$-centrifugal speed, $\mathrm{T}_{\mathrm{m}}$-mold preheat temperature, $T_{\text {pour }}$ - pouring temperature.

Figure 38 shows the optimum conditions for maximum properties. Also, Figs. 39 and 40 displayed the effect of different parameters on the hardness and tensile strength of FGAMC. Based on the parameters mentioned above, a linear regression model has been successfully derived. This model will facilitate the researchers to fabricate the FGAMCs with exceptional properties.

\section{Future scope for research work}

Many research have been carried out to fabricate bulk continuous FGAMCs through various processing routes such as powder metallurgy and casting. Continuous FGAMCs production through centrifugal casting technique combines these two routes as it uses reinforcement material in powder form, distributed uniformly into a liquid metal matrix. This mixture of liquid-particle is then poured into a rotating die of the centrifugal casting machine to obtain the desired gradient until solidification. Centrifugal casting is economically and qualitatively better than other functionally graded material processing techniques such as additive manufacturing (laser cladding, laser melt deposition) and chemical vapor deposition method. Due to such benefits, the centrifugal casting method to produce FGAMCs has enticed industries and researchers. In the past researches, mainly enhancement in mechanical and tribological behaviors and smoothness of gradient distribution 


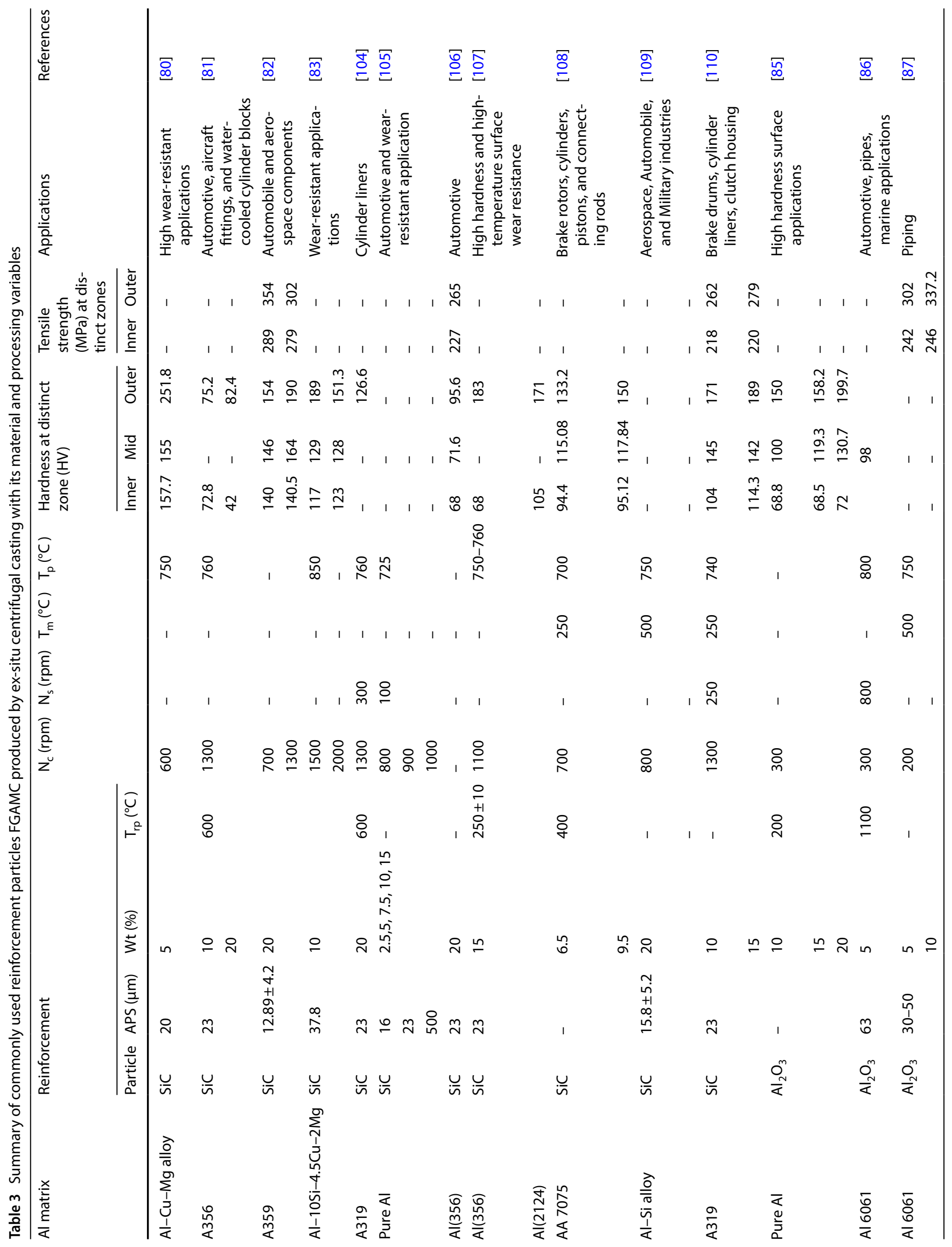




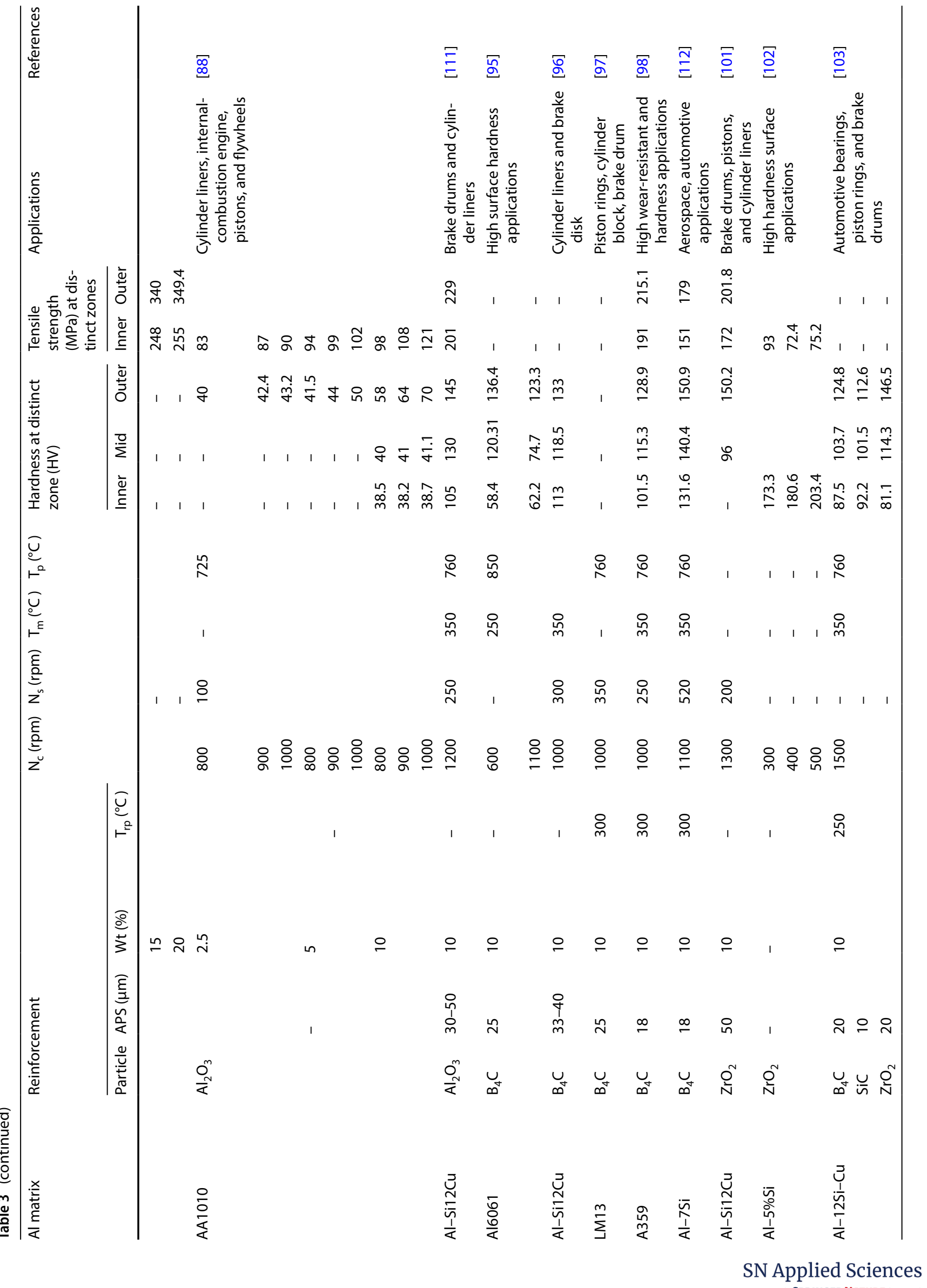


of reinforcement particles inside the aluminum matrix through centrifugal casting have been reported by several researchers. Many other properties, such as corrosion, fatigue, vibration, and thermo-mechanical behaviors, can also be needed to investigate. Figure 41 shows the description of research gaps in the production of FGAMC through the ex-situ centrifugal casting technique.

As already mentioned in the introduction, FGAMC production through centrifugal casting consists of two processing variables-material and process variables. Material variables involve reinforcement (type, size, shape, and weight fraction) and matrix (type and weight fraction), and process variables include pouring temperature, particle and mold preheat temperature, centrifugal speed, stirring speed, stirring time. The influences of these variables on various characteristics are needed to investigate further as limited researches have been reported in this direction. Also, the restricted investigations on hybrid FGAMCs have been carried out, so there are possibilities to explore this area.

Another research direction which is needed to be explored is the simulation of the centrifugal casting process to produce FGMs with an addition to the predetermination of various mechanical properties. Numerical modeling and simulation not only offers prediction in the behavior of different parameters involves during the processing of FGM through the centrifugal casting method but can also determine the effect of forces, mechanical and thermal stresses, vibrations, fatigue, wear, and other properties of the FGM component virtually and relatively in very low cost and time-saving method compared to the experimental casting process. Two modeling approaches can be used for analysis purposes - analytical and numerical methods. Analytical and numerical models can be developed to understand the behavior of fluid flow and particle motion in the viscous liquid metal under the influence of centrifugal forces to forecast and improve the gradation in the FGM. For the numerical analysis, ANSYS Fluent, Flow 3D, ProCast, and ABAQUS software packages can be utilized. To validate the result obtained by numerical simulation, analytical approach programming software such as MATLAB and Python can be used. Thus, the quality of the FGM can be predetermined using the simulation without casting.

\section{Summary and conclusion}

Limited works have been carried out on the fabrication and investigation of the continuous FGMs using centrifugal castings. There are various parameters involved during the synthesis process under the centrifugal casting technique-primarily material and process variables. The investigations on the mechanical and tribological characteristics of FGAMCs with different reinforcement particles under various processing variables are summarized in Tables 2 and 3. Moreover, various strengthening mechanisms and their implications to the mechanical properties have been discussed, and, thus, the correlation between them is summarized.

Researches within the last few years have concluded that their primary focus on investigating the mechanical and tribological behavior of FGAMC. A regression model has been established in order to optimize the parameters involved in the processing of FGAMC in Sect. 3, and thus, it was observed that the majority of the investigations had given the maximum values of hardness and tensile strength under reinforcement with 10-15 wt\%, average particle size $18-50 \mu \mathrm{m}$, mold preheating temperature $250-350{ }^{\circ} \mathrm{C}$, centrifugal speed $600-1300 \mathrm{rpm}$, and pouring temperature in the range of $740-760^{\circ} \mathrm{C}$. It is concluded from Figs. 38,39 and 40 that the average particle size has a significant contribution to the improvement of tensile strength, but the negligible effect as in the case of hardness enhancement and likewise, an increase in the weight fraction of the reinforcement particle improves the hardness and tensile strength. Besides, the increase in centrifugal speed and mold temperature showed a reduction in mechanical properties.

High pouring temperature contributed to the enhancement of tensile strength, whereas, decrement in hardness and also, it was found that the density of reinforcement particle, and matrix material, influences the microstructural, mechanical, and wear properties improvement either at the inner or outer region.

The important and critical mechanical properties such as tensile properties, hardness, and tribological properties have not been extensively studied and reported for FGAMCs. This critical review article will help the researchers to produce and study the influence of various ceramic reinforcement FGAMCs synthesized through the ex-situ 


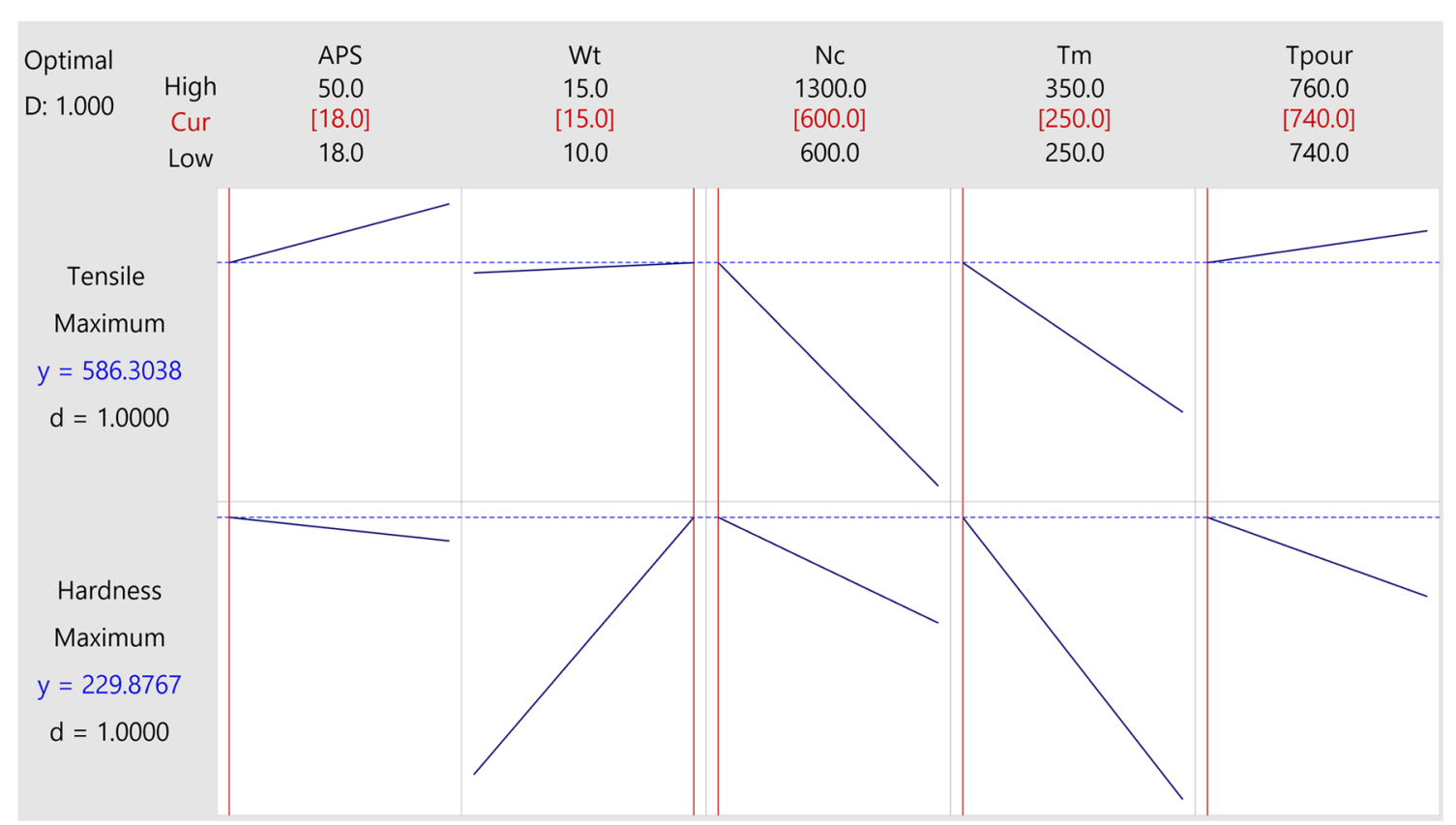

Fig. 38 Optimum conditions for maximum mechanical properties

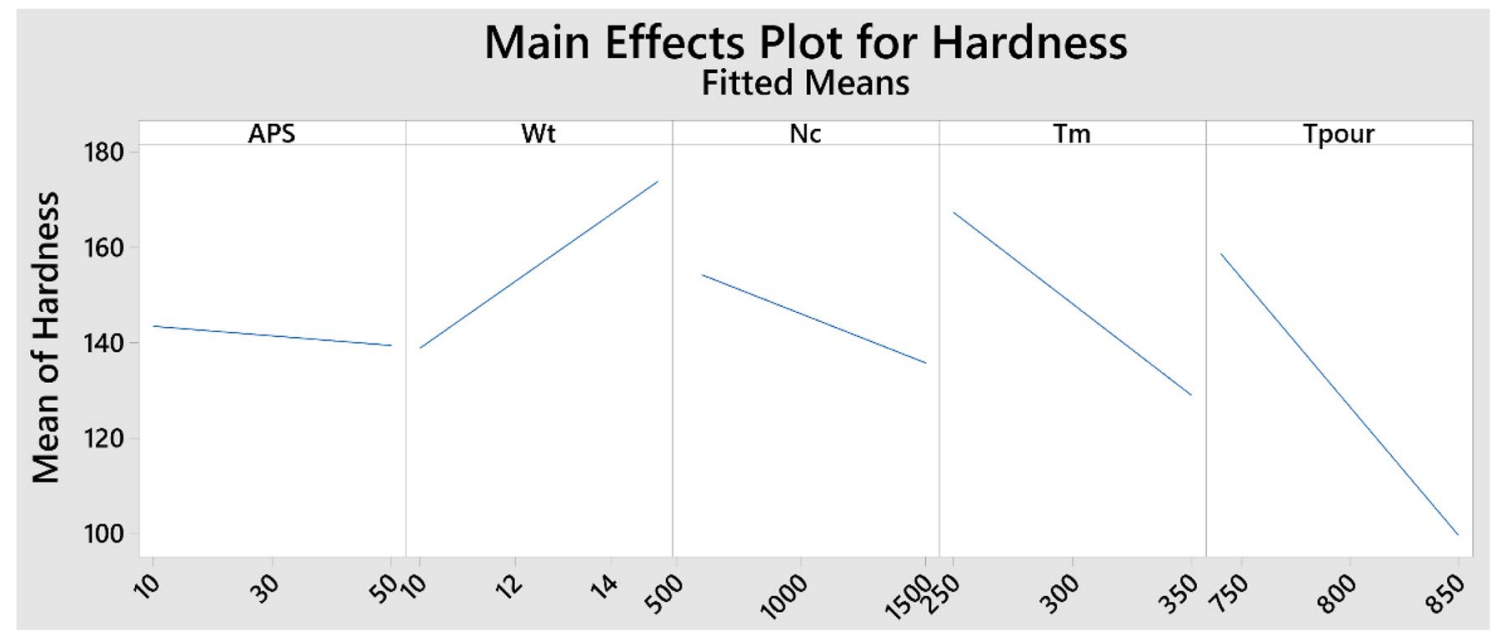

Fig. 39 Effect of different parameters on the hardness of FGAMC 


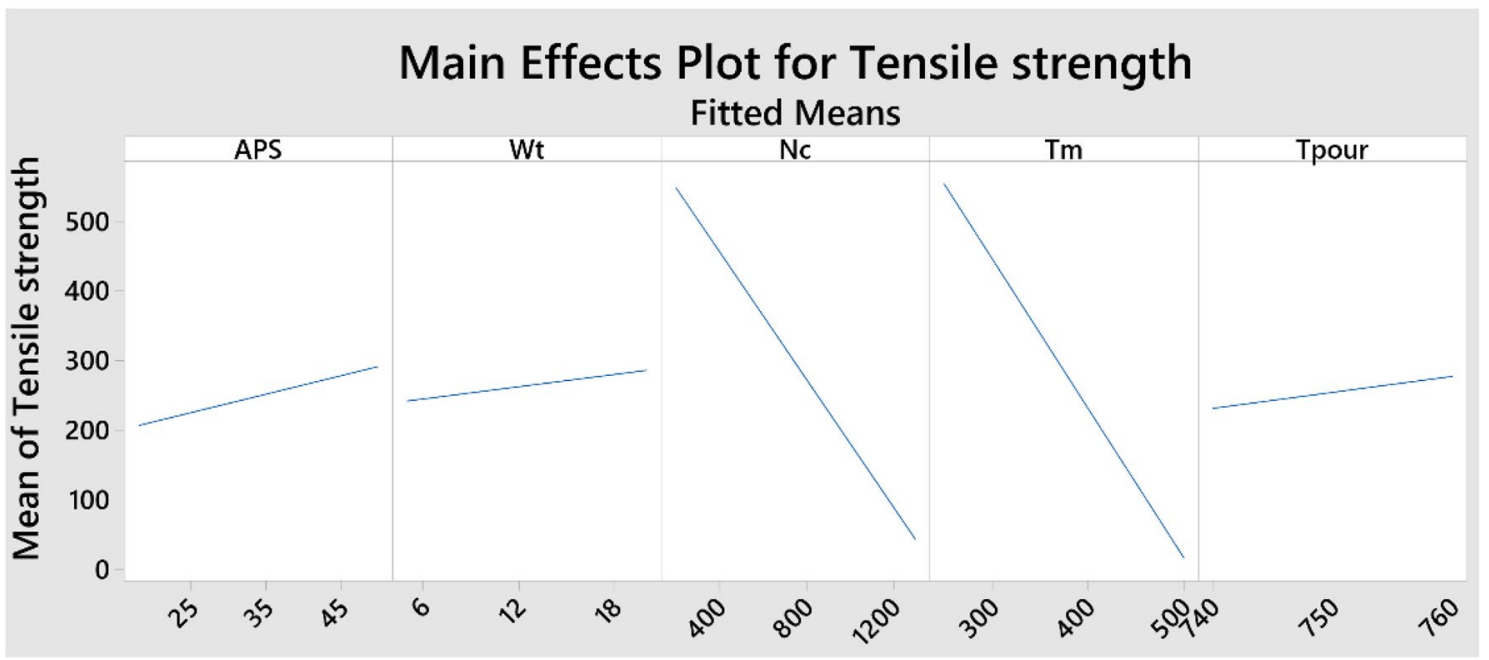

Fig. 40 Effect of different parameters on tensile strength of FGAMC

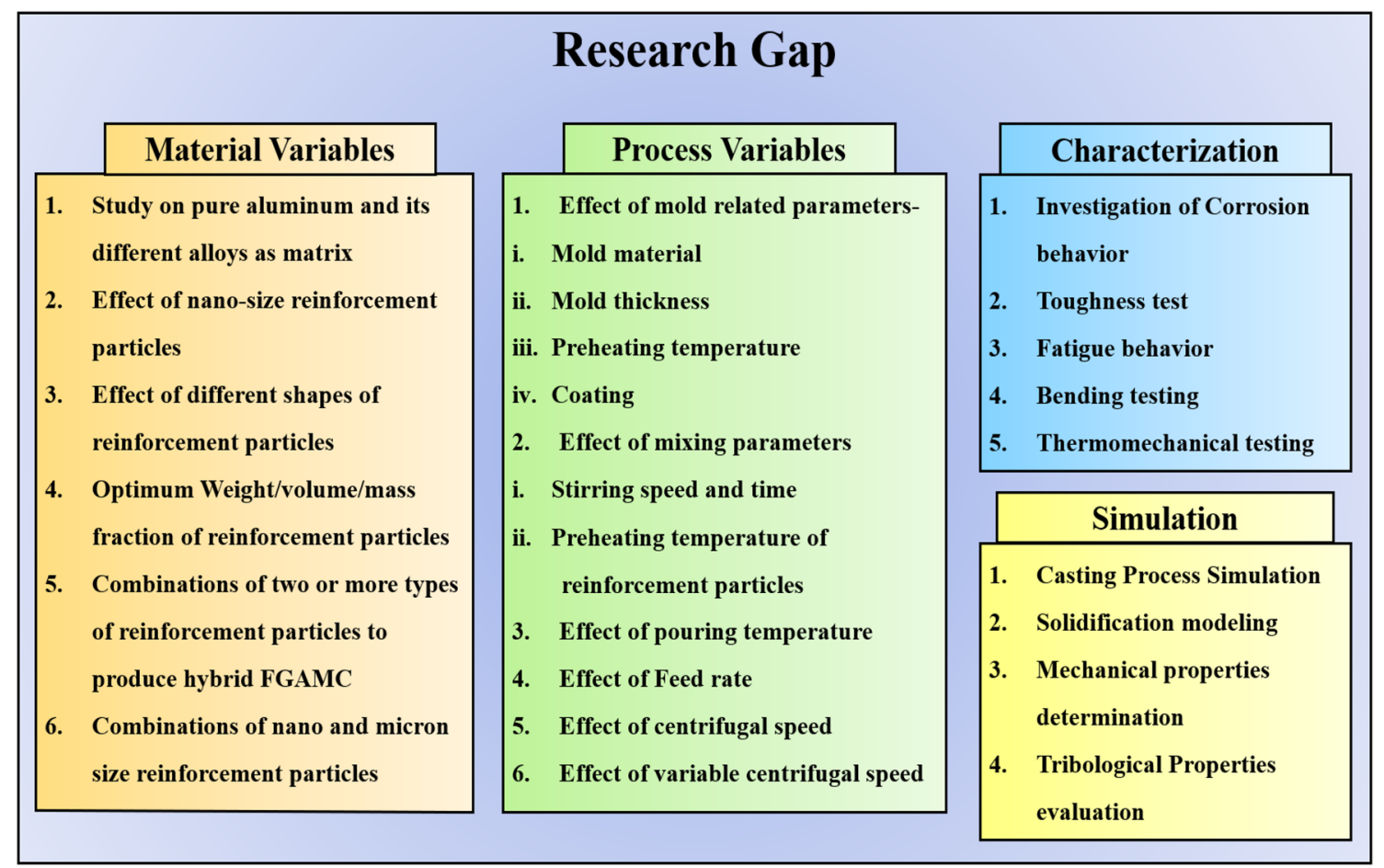

Fig. 41 Research gap in ex-situ centrifugal casting to produce FGAMC

centrifugal casting technique considering its materials and processing parameters.

Acknowledgements The authors would like to acknowledge the Department of Metallurgical and Materials Engineering, National Institute of Technology, Raipur.

Funding This study received no specific grant from any funding agency in the public, commercial, or not-for-profit sectors.

\section{Compliance with ethical standards}

Conflict of interest The authors declare that there is no conflict of interest.

Open Access This article is licensed under a Creative Commons Attribution 4.0 International License, which permits use, sharing, adaptation, distribution and reproduction in any medium or format, as long as you give appropriate credit to the original author(s) and the 
source, provide a link to the Creative Commons licence, and indicate if changes were made. The images or other third party material in this article are included in the article's Creative Commons licence, unless indicated otherwise in a credit line to the material. If material is not included in the article's Creative Commons licence and your intended use is not permitted by statutory regulation or exceeds the permitted use, you will need to obtain permission directly from the copyright holder. To view a copy of this licence, visit http://creativecommons .org/licenses/by/4.0/.

\section{References}

1. Williams ES, Karun AS (2016) Principles and baseline knowledge of functionally graded aluminum matrix materials (FGAMMs): fabrication techniques and applications. https:// doi.org/10.4028/www.scientific.net/JERA.26.47

2. Ichikawa K (ed) (2001) Functionally graded materials in the $21 \mathrm{st}$ century: a workshop on trends and forecasts, 1st ed. https:// doi.org/10.1007/978-1-4615-4373-2

3. Zhao N, Qiu PY, Cao LL (2012) Development and application of functionally graded material. Adv Mater Res 562-564:371-375

4. Mahamood RM, Akinlabi ET (2017) Functionally graded materials. https://doi.org/10.1007/978-3-319-53756-6

5. Singh R, Bhavar V, Kattire $P$, Thakare $S$, Patil S, Singh RKP (2017) A review on functionally gradient materials (FGMs) and their applications. IOP Conf Ser Mater Sci Eng. https://doi. org/10.1088/1757-899X/229/1/012021

6. Pelleg J (2009) Mechanical properties of ceramics. Springer Int Publ Switz. https://doi.org/10.3901/JME.2001.03.078

7. Naebe M, Shirvanimoghaddam K (2016) Functionally graded materials: A review of fabrication and properties. Appl Mater Today 5:223-245

8. Noda N (1999) Thermal stresses in functionally graded materials. J Therm Stress 22:477-512

9. Ebrahimi $F$ (2016) Advances in functionally graded materials and structures. ExLi4EvA

10. Meena R, Meena A, Meena P, Patnaik A (2018) Dry sliding wear analysis of aluminium alloy based cylinder liner by using linear reciprocating tribometer. Mater Res express. https://doi. org/10.1088/2053-1591/aaf6c2

11. Saleh B, Jiang J, Ma A, Song D, Yang D (2019) Effect of main parameters on the mechanical and wear behaviour of functionally graded materials by centrifugal casting: a review. Met Mater Int. https://doi.org/10.1007/s12540-019-00273-8

12. Chen L, Goto T (2003) Functionally graded materials. Handbook of advanced ceramics processes and their applications. Elsevier Academic Press, Amsterdam, pp 445-464

13. Lin $Q$, Chen F, Yin H (2017) Experimental and theoretical investigation of the thermo-mechanical deformation of a functionally graded panel. Eng Struct 138:17-26

14. Ebhota WS, Karun AS, Inambao FL (2016) Centrifugal casting technique baseline knowledge, applications, and processing parameters: overview. Int J Mater Res 107:960-969

15. Saleh B, Jiang J, Ma A, Song D, Yang D, Xu Q (2019) Review on the influence of different reinforcements on the microstructure and wear behavior of functionally graded aluminum matrix composites by centrifugal casting. Met Mater Int. https://doi. org/10.1007/s12540-019-00491-0

16. Yousefi M, Doostmohammadi H (2019) Spatial and microstructural dependence of mechanical properties and wear performance of functionally graded $\mathrm{Al}-\mathrm{TiAl}_{3}$ in situ composite. SN Appl Sci. https://doi.org/10.1007/s42452-019-1217-6

17. Popoola P, Farotade G, Fatoba O, Popoola O (2016) Laser engineering net shaping method in the area of development of functionally graded materials (FGMs) for aero engine applications - a review. Intech i:13

18. Koizumi M (1997) FGM activities in Japan. Compos Part B Eng 28:1-4

19. Al-Qrimli HF, Oshkour AA, Ismail FB, Mahdi FA (2015) Material design consideration for gear component using functional graded materials. Int J Mater Eng Innov 6:243-256

20. Zhang C, Chen F, Huang Z et al (2019) Additive manufacturing of functionally graded materials: a review. Mater Sci Eng $A$ 764:138209

21. Parihar RS, Setti SG, Sahu RK (2016) Recent advances in the manufacturing processes of functionally graded materials: a review. Sci Eng Compos Mater 25:309-336

22. Zhou ZJ, Yum YJ, Ge CC (2009) The recent progress of FGM on nuclear materials-design and fabrication of W/Cu functionally graded material high heat flux components for fusion reactor. Mater Sci Forum 631-632:353-358

23. Gupta A, Talha M (2015) Recent development in modeling and analysis of functionally graded materials and structures. Prog Aerosp Sci 79:1-14

24. Henriques B (2013) Inhomogeneous materials perform better: functionally graded materials for biomedical applications. J Powder Metall Min 02:2-3

25. Miyamoto $Y(1996)$ The applications of functionally graded materials in Japan. Mater Technol 11:230-236

26. del Val J, Arias-González F, Barro O, Riveiro A, Comesaña R, Penide J, Lusquiños F, Bountinguiza M, Quintero F, Pou J (2017) Functionally graded 3D structures produced by laser cladding. Procedia Manuf 13:169-176

27. El-Wazery MS, El-Desouky AR (2015) A review on functionally graded ceramic-metal materials. Environ Sci 6:1369-1376

28. Belmonte M, Gonzalez-Julian J, Miranzo P, Osendi MI (2009) Continuous in situ functionally graded silicon nitride materials. Acta Mater 57:2607-2612

29. Mahamood RM (2018) Laser metal deposition process of metals, alloys, and composite materials. Engineering materials and processes. Springer, Cham, pp 119-141

30. Kieback B, Neubrand A, Riedel H (2003) Processing techniques for functionally graded materials. Mater Sci Eng A 362:81-105

31. Pei YT, De HJT (2000) Functionally graded materials produced by laser cladding. Acta Mater 48:2617-2624

32. El-Galy IM, Saleh BI, Ahmed MH (2019) Functionally graded materials classifications and development trends from industrial point of view. SN Appl Sci. https://doi.org/10.1007/s42452-019-1413-4

33. Watanabe Y, Oshifumi I, Sato H, Miura-Fujiwara E (2009) A novel fabrication method for functionally graded materials under centrifugal force: the centrifugal mixed-powder method. Materials (Basel) 2:2510-2525

34. Fathi R, Ma A, Saleh B, Xu Q, Jiang J (2020) Investigation on mechanical properties and wear performance of functionally graded AZ91-SiCp composites via centrifugal casting. Mater Today Commun 24:101169

35. Du Z, Fu H, Fu H, Xiao Q (2005) A study of ceramic-lined compound copper pipe produced by SHS-centrifugal casting. Mater Lett 59:1853-1858

36. Chumanov IV, Anikeev AN, Chumanov VI (2015) Fabrication of functionally graded materials by introducing wolframium carbide dispersed particles during centrifugal casting and examination of FGM's structure. Procedia Eng 129:816-820

37. Bo ZY, Ming LC, Wang K, Hua ZM, Xie Y (2010) Characteristics of two Al-based functionally gradient composites reinforced by primary Si particles and Si/in situ $\mathrm{Mg}_{2}$ Si particles in centrifugal casting. Trans Nonferrous Met Soc China (Engl Ed) 20:361-370

38. Rajan TPD, Pillai RM, Pai BC (2007) Centrifugal casting: a potential technique for making functionally graded materials and engineering components. India Foundry J 53:79-86 
39. Saad Mahmood Ali (2019) The effect of reinforced SiC on the mechanical properties of the fabricated hypoeutectic Al-Si alloy by centrifugal casting. Eng Sci Technol Int J. https://doi. org/10.1016/j.jestch.2019.02.009

40. Watanabe $Y$, Sato $H$ (2016) Review fabrication of functionally graded materials under a centrifugal force. In: Intech, p 13

41. Ebhota WS, Jen T-C (2018) Casting and applications of functionally graded metal matrix composites. Adv Cast Technol. https ://doi.org/10.5772/intechopen.71225

42. Raju PSS, Mehrotra SP (2000) Mathematical modeling of centrifugal casting of metal matrix composites. Mater Trans JIM 41:1626-1635

43. Bohacek J, Kharicha A, Ludwig A, Wu M (2014) Simulation of horizontal centrifugal casting: mold filling and solidification. ISIJ Int 54:266-274

44. Gallo R, Neff D (2008) ASM handbook: vol 15-casting. https:// doi.org/10.1361/asmhba0005300

45. Janco N (1988) Centrifugal casting. American Foundarymens Society Inc, Schaumburg

46. Watanabe Y, Sato H, Fukui Y (2008) Wear properties of intermetallic compound reinforced functionally graded materials fabricated by centrifugal solid-particle and in-situ methods. J Solid Mech Mater Eng 2:842-853

47. Saleh B, Jiang J, Fathi R, Al-hababi T, Xu Q, Wang L, Song D, Ma A (2020) 30 Years of functionally graded materials: an overview of manufacturing methods, applications and future challenges. Compos Part B Eng 201:108376

48. Pai BC, Rajan TPD (2014) Developments in processing of functionally gradient metals and metal-ceramic composites: a review. Acta Metall Sin Engl Lett 27:825-838

49. Kohli GS, Singh T (2015) Review of functionally graded materials. J Prod Eng 18:1-4

50. Miller WS, Humphreys FJ (1991) Strengthening mechanisms in particulate metal matrix composites. Scr Metall Mater 25:33-38

51. Pilone D, Pulci G, Paglia L, Mondal A, Marra F, Felli F, Brotzu A (2020) Mechanical behaviour of an $\mathrm{Al}_{2} \mathrm{O}_{3}$ dispersion strengthened $\gamma$ TiAl alloy produced by centrifugal casting. Metals (Basel) 10:1-12

52. Radhika N, Raghu R (2017) Characterization of mechanical properties and three-body abrasive wear of functionally graded aluminum LM25/Titanium carbide metal matrix composite. Materwiss Werksttech 48:882-892

53. Jojith R, Radhika N (2018) Fabrication of LM25/WC functionally graded composite for automotive applications and investigation of its mechanical and wear properties. J Braz Soc Mech Sci Eng 40:1-13

54. Arsenault RJ, Shi N (1986) Dislocation generation due to differences between the coefficients of thermal expansion. Mater Sci Eng 81:175-187

55. Wu C, Ma K, Wu J, Fang P, Luo G, Chen F, Shen Q, Zhang L, Schoenung JM, Lavernia EJ (2016) Influence of particle size and spatial distribution of $\mathrm{B}_{4} \mathrm{C}$ reinforcement on the microstructure and mechanical behavior of precipitation strengthened Al alloy matrix composites. Mater Sci Eng A 675:421-430

56. Wang M, Chen D, Chen Z, Wu Y, Wang F, Ma N, Wang H (2014) Mechanical properties of in-situ $\mathrm{TiB}_{2} / \mathrm{A} 356$ composites. Mater Sci Eng A 590:246-254

57. Limin J, Zhimin L, Daming X, Jingjie G (2016) Effects of centrifugal forces and casting modulus on structures and mechanical properties of Ti-6Al-4V alloy. Rare Met Mater Eng 45:581-587

58. Joshi SP, Ramesh KT (2007) An enriched continuum model for the design of a hierarchical composite. Scr Mater 57:877-880

59. Dai LH, Ling Z, Bai YL (2001) Size-dependent inelastic behavior of particle-reinforced metal-matrix composites. Compos Sci Technol 61:1057-1063
60. Sekine $H$, Chent $R$ (1995) A combined microstructure strengthening analysis of $\mathrm{SiC}_{\mathrm{p}} / \mathrm{Al}$ metal matrix composites. Composites 26:183-188

61. Vajd A, Samadi A (2019) Optimization of centrifugal casting parameters to produce the functionally graded $\mathrm{Al}-15 \mathrm{wt} \%$ $\mathrm{Mg}_{2} \mathrm{Si}$ composites with higher tensile properties. Int J Met. https://doi.org/10.1007/s40962-019-00394-1

62. Watanabe Y, Yamanaka N, Fukui Y (1998) Control of composition gradient in a metal-ceramic functionally graded material manufactured by the centrifugal method. Compos Part A Appl Sci Manuf 29:595-601

63. Zhang LM, Liu J, Yuan RZ, Hirai T (1995) Properties of TiCNi3Al composites and structural optimization of TiCNi3Al functionally gradient materials. Mater Sci Eng A 203:272-277

64. Mahmoodian R, Hamdi M, Hassan MA, Akbari A (2015) Mechanical and chemical characterization of a $\mathrm{TiC} / \mathrm{C}$ system synthesized using a focus plasma arc. PLoS ONE 10:1-10

65. Gowrishankar TP, Manjunatha LH, Sangmesh B (2019) Mechanical and wear behavior of Al6061 reinforced with graphite and TiC hybrid MMC's. Mater Res Innov 00:1-7

66. Lee CS, Lemberg JA, Cho DG, Roh JY, Ritchie RO (2010) Mechanical properties of $\mathrm{Si}_{3} \mathrm{~N}_{4}-\mathrm{Al}_{2} \mathrm{O}_{3} \mathrm{FGM}$ joints with 15 layers for high-temperature applications. J Eur Ceram Soc 30:1743-1749

67. Sharma P, Sharma S, Khanduja D (2015) Production and some properties of $\mathrm{Si}_{3} \mathrm{~N}_{4}$ reinforced aluminum alloy composites. J Asian Ceram Soc 3:352-359

68. Radhika N (2016) Comparison of the mechanical and wear behavior of aluminum alloy with homogeneous and functionally graded silicon nitride composites. Sci Eng Compos Mater 25:261-271

69. Radhika N, Raghu R (2016) Development of functionally graded aluminum composites using centrifugal casting and influence of reinforcements on mechanical and wear properties. Trans Nonferrous Met Soc China (Engl Ed) 26:905-916

70. Deppisch C, Liu G, Shang JK, Economy J (1997) Processing and mechanical properties of $\mathrm{AlB}_{2}$ flake reinforced $\mathrm{Al}$-alloy composites. Mater Sci Eng A 225:153-161

71. Radhika N, Raghu R (2016) Effect of abrasive medium on wear behavior of $\mathrm{Al} / \mathrm{AlB}_{2}$ functionally graded metal matrix composite. Tribol Online 11:487-493

72. Radhika N, Raghu R (2016) The mechanical properties and abrasive wear behavior of functionally graded aluminum/AIB composites produced by centrifugal casting. Part Sci Technol 35:575-582

73. Shalaby EAM, Churyumov AY (2017) Development and characterization of A359/AIN composites for automotive applications. J Alloys Compd 727:540-548

74. Templeton DW, Gorsich TJ, Timothy, Holmquist J, Holmquist TJ (2007) Computational study of a functionally graded ceramicmetallic armor. In: 23rd Int Symp Ballist, pp 1155-1163

75. Azadi M, Zolfaghari M, Rezanezhad S, Azadi M (2018) Effects of $\mathrm{SiO}_{2}$ nano-particles on tribological and mechanical properties of aluminum matrix composites by different dispersion methods. Appl Phys A Mater Sci Process 124:1-13

76. Radhika N, Raghu R (2016) Abrasive wear behavior of monolithic alloy, homogeneous, and functionally graded aluminum (LM25/AIN and LM25/SiO ${ }_{2}$ ) composites. Part Sci Technol 6351:1-11

77. Sam M, Radhika N (2019) Mechanical and tribological analysis of functionally graded aluminum hybrid composite using RSM approach. Mater Res Express. https://doi.org/10.1088/20531591/ab3168

78. Kumar V, Sharma V (2018) Effects of $\mathrm{SiC}, \mathrm{Al}_{2} \mathrm{O}_{3}$, and $\mathrm{ZrO}_{2}$ particles on the LBMed characteristics of $\mathrm{Al} / \mathrm{SiC}, \mathrm{Al} / \mathrm{Al}_{2} \mathrm{O}_{3}$, and $\mathrm{Al} / \mathrm{ZrO}_{2}$ MMCs prepared by stir casting process. Part Sci Technol 1:1-11 
79. Wang Z-G, Li C-P, Wang H-Y, Zhu J-N, Wang C, Jiang Q-C (2016) Wear and corrosion behavior of functionally graded nano-SiC/2014Al composites produced by powder metallurgy. J Mater Eng Perform. https://doi.org/10.1007/s1166 5-016-2466-9

80. Savaş Ö, Kayikci R, Fiçici F, Çolak M, Deniz G, Varol F (2014) Production of functionally graded $\mathrm{SiC} / \mathrm{Al}-\mathrm{Cu}-\mathrm{Mg}$ composite by centrifugal casting. Sci Eng Compos Mater 23:155-159

81. Karun AS, Rajan TPD, Pillai UTS, Pai BC, Rajeev VR, Farook A (2016) Enhancement in tribological behavior of functionally graded $\mathrm{SiC}$ reinforced aluminum composites by centrifugal casting. J Compos Mater 50:2255-2269

82. R. Rodri'guez-Castro, Wetherhold RC, Kelestemur MH, (1995) Microstructure and mechanical behavior of functionally graded

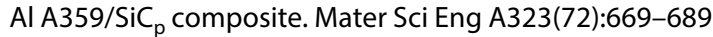

83. Vieira AC, Sequeira PD, Gomes JR, Rocha LA (2009) Dry sliding wear of Al alloy/SiC functionally graded composites: influence of processing conditions. Wear 267:585-592

84. Auerkari P (1996) Mechanical and physical properties of engineering alumina ceramics. VTT Tied. - Valt. Tek. Tutkimusk

85. Mer KKS, Ray S (2011) Low speed centrifugal casting of functionally graded solid cast ingot by anomalous particle distribution. AIP Conf Proc 1414:262-265

86. Junus S, Zulfia A (2016) Development of seamless pipe based on $\mathrm{Al} / \mathrm{Al}_{2} \mathrm{O}_{3}$ composite produced by stir casting and centrifugal casting. Mater Sci Forum 857:179-182

87. Prasad T (2011) Experimental investigation on the effect of particle loading on microstructural, mechanical and fractural properties of $\mathrm{Al} / \mathrm{Al}_{2} \mathrm{O}_{3}$ functionally graded materials. Int J Adv Eng Technol II:161-166

88. Saleh BI, Ahmed MH (2019) Development of functionally graded tubes based on pure $\mathrm{Al} / \mathrm{Al}_{2} \mathrm{O}_{3}$ metal matrix composites manufactured by centrifugal casting for automotive applications. Met Mater Int. https://doi.org/10.1007/s12540-01900391-3

89. Faisal MH, Prabagaran S (2018) Investigation on mechanical and wear properties of aluminum based metal matrix composite reinforced with $\mathrm{B}_{4} \mathrm{C}, \mathrm{Gr}$, and fly ash. Advanced manufacturing and materials science. Springer, Cham, pp 379-385

90. Liu S, Wang Y, Muthuramalingam T, Anbuchezhiyan G (2019) Effect of $\mathrm{B}_{4} \mathrm{C}$ and $\mathrm{MoS}_{2}$ reinforcement on microstructure and wear properties of aluminum hybrid composite for automotive applications. Compos Part B Eng 176:107329

91. Sekar K, Vasanthakumar P (2019) Mechanical properties of Al$\mathrm{Cu}$ alloy metal matrix composite reinforced with $\mathrm{B}_{4} \mathrm{C}$, graphite, and wear rate modeling by Taguchi method. Mater Today Proc 18:3150-3159

92. Manjunatha B, Niranjan HB, Satyanarayana KG (2018) Effect of amount of boron carbide on wear loss of Al-6061 matrix composite by Taguchi technique and Response surface analysis. IOP Conf Ser Mater Sci Eng. https://doi.org/10.1088/1757899X/376/1/012071

93. Bahrami A, Soltani N, Pech-Canul MI, Soltani S, González LA, Gutié Rrez CA, Tapp J, Mö Ller A, Gurlo A (2018) Bilayer graded $\mathrm{Al} / \mathrm{B}_{4} \mathrm{C} /$ rice husk ash composite: wettability behavior, thermo-mechanical, and electrical properties. https://doi. org/10.1177/0021998318769993

94. Gupta PK, Srivastava RK (2018) Fabrication of ceramic reinforcement aluminum and its alloys metal matrix composite materials: a review. Mater Today Proc 5:18761-18775

95. Rao AG, Mohape M, Katkar VA, Gowtam DS, Deshmukh VP, Shah AK (2010) Fabrication and characterization of aluminum (6061)-boron-carbide functionally gradient material. Mater Manuf Process 25:572-576
96. Radhika N, Raghu R (2015) Experimental investigation on abrasive wear behavior of functionally graded aluminum composite. J Tribol 137:1-7

97. Muddamsetty LVP, Radhika N (2016) Effect of heat treatment on the wear behaviour of functionally graded $\mathrm{LM} 13 / \mathrm{B}_{4} \mathrm{C}$ composite. Tribol Ind 38:108-114

98. Radhika N, Sasikumar J, Sylesh JL, Kishore R (2019) Dry reciprocating wear and frictional behavior of $\mathrm{B}_{4} \mathrm{C}$ reinforced functionally graded and homogenous aluminum matrix composites. J Mater Res Technol 9:1578-1592

99. Kunimine T, Sato H, Miura-Fujiwara E, Watanabe $Y$ (2014) New processing routes for functionally graded materials and structures through combinations of powder metallurgy and casting. In: Adv. Funct. Graded Mater. Struct. IntechOpen, p 64

100. Ângela C, Volpato M, Gustavo L, Garbelotto DA, Fredel MC, Bondioli F, Emilia R (2012) Application of zirconia in dentistry: biological, mechanical, and optical considerations. Adv Ceram Electr Magn Ceram Bioceram Ceram Environ. https://doi. org/10.5772/726

101. Radhika N, Raghu R (2015) Mechanical and tribological properties of functionally graded aluminum/zirconia metal matrix composite synthesized by centrifugal casting. Int J Mater Res 106:1174-1181

102. Sen S, Sharma AR, Parihar D, Mahato AK, Thakur MK (2018) Effect of reinforcement of $\mathrm{ZrO}_{2}$ on mechanical properties of Al-5\%Si cast using vertical centrifugal casting. Int J Eng Sci Res Technol 7:549-558

103. Jojith R, Radhika N (2019) Enhancement of mechanical and sliding wear properties of functionally graded $\mathrm{Al}-12 \mathrm{Si}-\mathrm{Cu}$ composites. Mater Res express 6:1-13

104. Jayakumar E, Praveen AP, Rajan TPD, Pai BC (2018) Studies on tribological characteristics of centrifugally cast $\mathrm{SiC}_{\mathrm{p}}$-reinforced functionally graded A319 aluminum matrix composites. Trans Indian Inst Met. https://doi.org/10.1007/s12666-018-1442-5

105. El-Galy IM, Ahmed MH, Bassiouny BI (2017) Characterization of functionally graded $\mathrm{Al}-\mathrm{SiC}_{\mathrm{p}}$ metal matrix composites manufactured by centrifugal casting. Alex Eng J 56:371-381

106. Rajan TPD, Pillai RM, Pai BC (2008) Centrifugal casting of functionally graded aluminum matrix composite components. Int J Cast Met Res 21:214-218

107. Rajan TPD, Pillai RM, Pai BC (2010) Characterization of centrifugal cast functionally graded aluminium-silicon carbide metal matrix composites. Mater Charact 61:923-928

108. Ram Prabhu T (2017) Processing and properties evaluation of functionally continuous graded $7075 \mathrm{Al}$ alloy/SiC composites. Arch Civ Mech Eng 17:20-31

109. Wang K, Zhang ZM, Yu T, He NJ, Zhu ZZ (2017) The transfer behavior in centrifugal casting of $\mathrm{SiC}_{\mathrm{p}} / \mathrm{Al}$ composites. J Mater Process Technol 242:60-67

110. Jayakumar E, Jacob JC, Rajan TPD, Joseph MA, Pai BC (2016) Processing and characterization of functionally graded aluminum (A319) - $\mathrm{SiC}_{\mathrm{p}}$ metallic composites by centrifugal casting technique. Metall Mater Trans A Phys Metall Mater Sci 47:4306-4315

111. Radhika N (2017) Mechanical properties and abrasive wear behaviour of functionally graded $\mathrm{Al}-\mathrm{Si} 12 \mathrm{Cu} / \mathrm{Al}_{2} \mathrm{O}_{3}$ metal matrix composite. Trans Indian Inst Met 70:145-157

112. Jojith R, Radhika N (2019) Investigation of mechanical and tribological behaviour of heat-treated functionally graded Al-7Si/B ${ }_{4}$ C composite. Silicon. https://doi.org/10.1007/s1263 3-019-00294-3

Publisher's Note Springer Nature remains neutral with regard to jurisdictional claims in published maps and institutional affiliations. 